\title{
Caenorhabditis elegans AGXT-1 is a mitochondrial and temperature-adapted ortholog of peroxisomal human AGT1: New insights into between-species divergence in glyoxylate metabolism.
}

\author{
Noel Mesa-Torres ${ }^{1 * \dagger}$, Ana C. Calvo ${ }^{2 \dagger}$, Elisa Oppici ${ }^{3}$, Nicholas Titelbaum ${ }^{1,2}$, Riccardo \\ Montioli ${ }^{3}$, Antonio Miranda-Vizuete ${ }^{4}$, Barbara Cellini ${ }^{3}$, Eduardo Salido ${ }^{5}$ and Angel L. Pey ${ }^{1 *}$. \\ ${ }^{1}$ Department of Physical Chemistry, Faculty of Sciences, University of Granada, Av. Fuentenueva s/n, \\ 18071 Granada, Spain. \\ ${ }^{2}$ Program in Cellular Neuroscience, Neurodegeneration, and Repair, Department of Cell Biology, Yale \\ University School of Medicine, New Haven, CT 06536, USA. \\ ${ }^{3}$ Department of Neurological, Biomedical and Movement Sciences, Section of Biological Chemistry, \\ University of Verona, Strada Le Grazie 8, 37134 Verona, Italy. \\ ${ }^{4}$ Instituto de Biomedicina de Sevilla, Hospital Universitario Virgen del Rocío/Consejo Superior de \\ Investigaciones Científicas / Universidad de Sevilla, 41013 Sevilla, Spain. \\ ${ }^{5}$ Centre for Biomedical Research on Rare Diseases (CIBERER), University Hospital of the Canary Islands, \\ and CIBICAN, University of La Laguna, 38320 Tenerife, Spain
}

\section{Abstract}

In humans, glyoxylate is an intermediary product of metabolism, whose concentration is finely balanced. Mutations in peroxisomal alanine:glyoxylate aminotransferase (hAGT1) cause primary hyperoxaluria type 1 , which results in glyoxylate accumulation that is converted to toxic oxalate. In contrast, glyoxylate is used by the nematode $C$. elegans through a glyoxylate cycle to by-pass the decarboxylation steps of the tricarboxylic acid cycle and thus contributing to energy production and gluconeogenesis from stored lipids. To investigate the differences in glyoxylate metabolism between humans and $C$. elegans and to determine whether the nematode might be a suitable model for $\mathrm{PH} 1$, we have characterized here the predicted nematode ortholog of hAGT1 (AGXT-1) and compared its molecular properties with those of the human enzyme. Both enzymes form active PLPdependent dimers with high specificity towards alanine and glyoxylate, and display similar

\footnotetext{
“Corresponding authors: noelmesatorres@gmail.com, angelpey@ugr.es

${ }^{\dagger}$ These authors contributed equally to this work
} 
three-dimensional structures. Interestingly, AGXT-1 shows 5-fold higher activity towards the alanine/glyoxylate pair than hAGT1. Thermal and chemical stability of AGXT-1 is lower than that of hAGT1, suggesting temperature-adaptation of the nematode enzyme linked to the lower optimal growth temperature of $C$. elegans. Remarkably, in vivo experiments demonstrate the mitochondrial localization of AGXT-1 in contrast to the peroxisomal compartmentalization of hAGT1. Our results support the view that the different glyoxylate metabolism in the nematode is associated with the divergent molecular properties and subcellular localization of the alanine:glyoxylate aminotransferase activity.

Keywords. Primary hyperoxaluria; enzyme kinetics; substrate specificity; protein stability; conformational disease.

\section{Introduction}

Glyoxylate is an intermediary product of metabolism in humans, which is formed

3 from precursors such as glycine, glycolate, hydroxypyruvate and hydroxyproline. Among

4 mammals, alanine:glyoxylate aminotransferase (AGT) protein compartmentalization is

5 linked to metabolism of glyoxylate precursors, varying from mainly mitochondrial in

6 carnivorous, peroxisomal in herbivorous and located in both organelles in omnivorous [1].

7 The human AGXT gene encodes an alanine:glyoxylate aminotransferase enzyme (hAGT1;

8 E.C. 2.6.1.44) that is responsible for glyoxylate detoxification in peroxisomes of

9 hepatocytes [2] thus balancing the glyoxylate concentration. The human genome encodes

10 a second protein with alanine:glyoxylate aminotransferase activity named hAGT2 [3] that

11 catalyses multiple aminotransferase reactions [4,5] and might be involved in the 12 metabolism of glyoxylate within the mitochondria. hAGT1 is a pyridoxal 5'-phosphate 13 (PLP)- dependent enzyme that catalyses the amino transfer from L-alanine to glyoxylate 
14 resulting into pyruvate and glycine and this reaction is largely shifted towards glycine

15 formation [6]. Mutations in AGXT gene cause primary hyperoxaluria type 1 (PH1), an error

16 of amino acid metabolism inherited in an autosomal recessive manner [2]. $\mathrm{PH} 1$ results in

17 the accumulation of glyoxylate in hepatocytes where it is oxidized to oxalate (a metabolic-

18 end product in humans) causing progressive renal failure and ultimately leading to a build-

19 up of oxalate and life-threatening oxalate precipitation [2,7]. Currently, the best method to

20 treat $\mathrm{PH} 1$ is a double liver and kidney transplantation, but this treatment often shows

21 significant rates of morbidity and mortality.

After the complete sequencing of Caenorhabditis elegans genome, early estimations indicated that around $74 \%$ of human gene sequences had nematode

24 counterparts [8]. Therefore, a lot of effort was put into identifying potential nematode 25 orthologs to human genes. As a result, using an in silico search of genes associated with 26 inborn errors of metabolism in humans, an open-reading frame termed as T14D7.1 was 27 predicted as an ortholog of human AGXT gene [9]. The T14D7.1 gene (now renamed as 28 agxt-1) is located on chromosome 2 and it is organized into 11 exons 29 (WBGene00011767), whose conceptual translation results into a 405 amino acids protein 30 (AGXT-1). Unlike humans, the nematode $C$. elegans has an active glyoxylate cycle (GC) 31 [10] that allows to bypass the decarboxylation steps of the tricarboxylic acid (TCA) cycle 32 [11] , thus linking catabolic and biosynthetic capacities. In the nematode, the key enzyme 33 of this cycle is a single bi-functional enzyme (ICL-1), which has isocitrate lyase activity $(\mathrm{N}$ 34 terminal domain) and malate synthase activity (C-terminal domain) [12] that are regulated 35 in a developmentally specific manner [13,14] .

36 We herein present data supporting that the divergent glyoxylate metabolism 37 between humans and the nematode $C$. elegans could involve different molecular 38 properties and subcellular localization of their respective AGT enzymes. Further, we 
demonstrate that even though AGXT-1 and hAGT1 proteins have similar quaternary

40 structure and substrate specificities, AGXT-1 displays higher specific activity and lower

41 protein stability, possibly reflecting temperature adaptation of the nematode enzyme. In

42 vivo studies demonstrate the mitochondrial localization of AGXT-1 in contrast to the

43 peroxisomal functional environment of hAGT1. In this work, we provide novel insights into

44 the evolutionary changes in protein stability, roles of AGT proteins and the divergence of

45 glyoxylate metabolism between vertebrates and invertebrates.

\section{Materials and Methods}

C. elegans AGXT-1 cloning, expression and purification. The agxt-1 ORF was

amplified from a $C$. elegans cDNA library and cloned into a pET-28 (Novagen) vector using

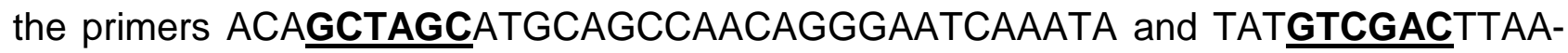
ACCAAATTAGGATCCGATGGACTT forward and reverse respectively and restriction enzymes Nhel-HF and Sall-HF (New England Biolabs). This construct incorporates a Histag sequence at the N-terminal domain of AGXT-1. E. coli BL21(DE3) competent cells were transformed with the plasmid and were grown in LB medium supplemented with 30 $\mu \mathrm{g} \cdot \mathrm{ml}^{-1}$ kanamycin. Overnight cultures were diluted 40 -fold in fresh LB-kanamycin for $3 \mathrm{~h}$ at $37^{\circ} \mathrm{C}$ and induced at $4^{\circ} \mathrm{C}$ by adding IPTG $0.5 \mathrm{mM}$ for $8 \mathrm{~h}$. Cells were harvested and lysed by sonication in binding buffer $\left(20 \mathrm{mM} \mathrm{NaH}_{2} \mathrm{PO}_{4}, 200 \mathrm{mM} \mathrm{NaCl}, 50 \mathrm{mM}\right.$ imidazole,

$57 \mathrm{pH}$ 7.4) supplemented with protease inhibitors (EDTA-free protease inhibitor cocktail, 58 Roche). Soluble extracts obtained after ultracentrifugation at 70,000 x $g$ were loaded onto 59 an IMAC columns (GE Healthcare) and eluted with binding buffer supplemented with 500 $60 \mathrm{mM}$ imidazole. His-AGXT-1 was further purified by size exclusion chromatography using a 61 HiLoad $^{\mathrm{TM}}$ 16/60 Superdex ${ }^{\mathrm{TM}} 200$ column running in 20 mM Hepes (2-[4-(262 hydroxyethyl)piperazin-1-yl]ethanesulfonic acid), $200 \mathrm{mM} \mathrm{NaCl}, \mathrm{pH}$ 7.4. The concentration 63 of His-AGXT-1 (hereafter AGXT-1) protein was evaluated using a sequence-based 
64 extinction coefficient of $0.763 \mathrm{ml} \cdot \mathrm{mg}^{-1} \cdot \mathrm{cm}^{-1}$ at $280 \mathrm{~nm}$ [15]. The purification of hAGT1 was

65 performed as described previously [16]. Isolation of apo-forms of both enzymes was 66 attempted by using the protocol previously described [17]. PLP concentration was 67 calculated by using a molar extinction coefficient of $4,900 \mathrm{M}^{-1} \cdot \mathrm{cm}^{-1}$ at $388 \mathrm{~nm}$ [18].

68 Spectroscopic analyses. All the spectroscopic assays were performed in a $20 \mathrm{mM}$ 69 Hepes, $200 \mathrm{mM} \mathrm{NaCl}, \mathrm{pH} 7.4$ buffer at 25ㅇ․ UV-visible absorption spectroscopy was 70 performed in an Agilent 8453 diode-array spectrophotometer using cuvettes with a path 71 length of $3 \mathrm{~mm}$ and $20 \mu \mathrm{M}$ protein (in subunit). Near-UV/visible circular dichroism 72 measurements were performed in a Jasco $\mathrm{J}$-710 spectropolarimeter by using 5-mm path 73 length cuvettes with $20 \mu \mathrm{M}$ protein (in subunit). Dynamic light scattering was carried out 74 using a protein concentration of $5 \mu \mathrm{M}$ (in subunit) in the presence of $50 \mu \mathrm{M}$ PLP in a 75 Zetasizer Nano ZS (Malvern Inc.) with 3-mm path length cuvettes and applying the Stokes76 Einstein equation assuming a spherical shape for the scattering particles.

77 Enzyme activity measurements. The overall transaminase activity was measured at $7837^{\circ} \mathrm{C}$ with a protein concentration of $2.5 \mu \mathrm{g} \cdot \mathrm{ml}^{-1}$ in the presence of $150 \mu \mathrm{M}$ PLP in $0.1 \mathrm{M}$ 79 phosphate buffer $\mathrm{pH}$ 8. The time of the reaction was 2 minutes and the substrate 80 concentration was $0.25-2 \mathrm{mM}$ glyoxylate and 0-100 mM L-alanine. Pyruvate formation was 81 evaluated following the oxidation of NADH at $340 \mathrm{~nm}$ by a coupled enzyme assay using 82 lactate dehydrogenase [19] during 3 minutes at $37^{\circ} \mathrm{C}$. Global fittings were performed 83 according to a double-displacement mechanisms $[6,16]$. To determine the $\mathrm{pH}$ 84 dependence, activity measurements were performed using this coupled assay in the 85 presence of $2 \mathrm{mM}$ glyoxylate and $100 \mathrm{mM}$ L-alanine at $37^{\circ} \mathrm{C}$ in the following buffers: 100 $86 \mathrm{mM}$ Hepes (pH 7-8), MES (2-(N-morpholino)ethanesulfonic acid, $\mathrm{pH}$ 6-6.5), acetate $(\mathrm{pH}$ $874.5-5.5)$ or formiate $(\mathrm{pH} 3-4)$. The time of the transamination reaction was set at 1.5 88 minutes ( $\mathrm{pH} 7-8), 4$ minutes $(\mathrm{pH}$ 6-6.5) and 10 minutes $(\mathrm{pH} 3.5-5-5)$. The dependence of 
specific activity on temperature was measured at $15,20,25,30$ and $37^{\circ} \mathrm{C}$ with reaction

90 times from 2 to 10 minutes. To investigate the substrate specificity, the overall

91 transamination reaction was measured in the presence of different amino acids (L-alanine,

92 L-serine, L-arginine, L-glutamate, L-aspartate and L-phenylalanine) and ketoacids

93 (glyoxylate and pyruvate) by incubating the enzymes $\left(2.5-100 \mu \mathrm{g} \cdot \mathrm{ml}^{-1}\right)$ with the amino acid

94 at $100 \mathrm{mM}$, the ketoacid at $2 \mathrm{mM}$ and in the presence of $200 \mu \mathrm{M}$ PLP in $0.1 \mathrm{M}$ phosphate

95 buffer, $\mathrm{pH} 8$ and $37^{\circ} \mathrm{C}$. Aliquots of each reaction mixture were collected at various times

96 and the reaction was stopped by adding $10 \%(\mathrm{w} / \mathrm{v})$ trichloroacetic acid. The amount of

97 ketoacid consumed was determined by HPLC after derivatization with 2,4-

98 dinitrophenylhydrazine as previously described [20].

99 Differential scanning calorimetry. DSC experiments were performed and analysed as 100 previously described for hAGT1 [17,21]. Briefly, the model considers the irreversible 101 denaturation of the native protein to a final state that cannot fold back, and this kinetic 102 conversion is characterized by a first-order rate constant $k$, which changes with 103 temperature according to the Arrhenius equation. The half-life at any temperature can thus 104 be obtained from extrapolation of $k$ to a given temperature following the Arrhenius plot and 105 determined as $t_{1 / 2}=\ln (2) / k$.

106 Urea denaturation. Urea denaturation of AGXT-1 and hAGT1 was performed by 107 incubating the enzymes (5 $\mu \mathrm{M}$ in protein subunit) in $20 \mathrm{mM}$ Hepes, $200 \mathrm{mM} \mathrm{NaCl}, 1 \mathrm{mM}$ 108 TCEP (Tris(2-carboxyethyl)phosphine) pH 7.4 with urea at concentrations ranging from 0-8 109 M. Urea concentration was determined by refractive index measurements. Samples were 110 incubated at $25^{\circ} \mathrm{C}$ for $16 \mathrm{~h}$ and then denaturation was monitored by Far-UV circular 111 dichroism spectroscopy (200-260 nm; $1 \mathrm{~mm}$ quartz cuvettes). Refolding experiments were 112 performed by dilution of protein samples denatured in $8 \mathrm{M}$ urea solution with urea-free 
113 buffer and allowed to equilibrate at $25^{\circ} \mathrm{C}$ for $4 \mathrm{~h}$ prior to Far-UV CD spectroscopic 114 analyses.

115 Structural modelling. The structural model of AGXT-1 protein was obtained using the 116 Modeler v9.13 software, the AGXT-1 amino acids sequence and the crystal structure of 117 human hAGT1 (pdb 1H0C) protein as a template. The model refinement was performed by 118 energy minimization applying the CHARM27 force field of the MOE software. The 119 adjustment of the protonation state, the coordinate based isoelectric point calculation, the 120 electrostatic surface map drawing, the structural alignment and the images construction 121 were performed using MOE 2013 software (CCG group).

122 Strains. C. elegans worms were culture and handle as described before [22]. The 123 following strains were used: wild type N2 Bristol, UGR1 alpEx1 [Pmyo-3::tomm-20:: gfp, 124 Pmyo-3::agxt-1(50aa)::tagrfp, Punc-122::gfp], UGR3 alpEx3 [Pmyo-3:: tomm -20:: gfp, 125 Pmyo-3::agxt-1(100aa):: tagrfp, Punc-122:: gfp], UGR7 alpEx7 [Pmyo-3:: tomm -20:: gfp, 126 Pmyo-3:: tagrfp, Punc-122:: gfp], UGR9 agxt-1 (tm6307), UGR10 icl-1 (ok531), and 127 UGR11 agxt-1(tm6307); icl-1 (ok531).

128 Molecular biology and transgenic lines. The nucleotide sequence corresponding to the 129 first 50 and 100 amino acids of the agxt-1 cDNA sequence were amplified and cloned into 130 a gateway plasmid pDONR221 These clones were fused in frame with tagRFP 131 (monomeric RFP) and the unc-54 gene 3-UTR and expressed under the myo-3 promoter, 132 using the Multi Site Gateway Pro Plus Kit (ThermoFisher, catalogue number 11791-100 133 and 11789-013). These plasmids were injected at $5 \mathrm{ng} \cdot \mu^{-1}$ together with a plasmid 134 expressing the mitochondrial fusion construct TOMM-20::GFP under the control of the 135 same myo-3 promoter (kindly provided by Dr. Marc Hammarlund, Yale University) at 5 $136 \mathrm{ng} \cdot \mathrm{\mu l}^{-1}$ and the co-injection marker Punc-122::gfp. Transgenic animals were generated 137 using standard techniques [23]. 
Fluorescence and confocal image acquisition and analysis. Images of fluorescence fusion proteins were taken in live adults $C$. elegans nematodes using a 60X CFI Plan Apo

140 VC, numerical aperture 1.4, oil-immersion objective on an UltraView VoX spinning-disc 141 confocal microscope (PerkinElmer Life and Analytical Sciences). Worms were 142 synchronized 3 days prior to experiment, and first day of adulthood animals were 143 analysed. Animals were immobilized during image acquisition using $10 \mu \mathrm{M}$ Levamisol 144 (Sigma). Images were analysed using Volocity software (Improvision).

145 Glyoxylate and oxalate determination. C. elegans strains N2, UGR9, UGR10 and 146 UGR11 were grown on NGM plates supplemented with $10 \mathrm{mM}$ Sodium Glyoxylate 147 monohydrate (Sigma). When bacterial food was about to exhaust, mixed stage 148 populations of worms were washed out from the plates with M9 buffer several times to 149 clean the bacteria off and worm pellet was frozen at $-80^{\circ} \mathrm{C}$ overnight. Thawed pellet was 150 resuspended in 5 volumes of cold $10 \mathrm{mM}$ Hepes and $0.5 \%$ CHAPS buffer supplemented 151 with complete protease inhibitor cocktail (Roche) and sonicated. Lysates were centrifuged 152 at $14000 \mathrm{rpm}$ for $10 \mathrm{~min}$ at $4^{\circ}$ and supernatants were transferred into a new tube and 153 immediately frozen. To evaluate glyoxylate content, lysates were deproteinized by the 154 addition of $10 \%(\mathrm{w} / \mathrm{v})$ trichloroacetic acid and centrifuged at $13200 \mathrm{~g}$ for $2 \mathrm{~min}$. The amount 155 of glyoxylate present in supernatant was determined by HPLC analysis after derivatization 156 with 2,4.dinitrophenylhydrazyne as previously described [20]. The total protein content of 157 each lysate was determined before deproteinization by using the Bradford assay. Oxalate 158 content was evaluated by using the Oxalate Quantitative Enzymatic Color Test Kit (Greiner 159 Diagnostic $\mathrm{GmbH}$ ) following manufacturer's protocol.

\section{Results}

161 AGXT-1 is a mitochondrial protein. According to a protein sequence comparison, $C$. elegans AGXT-1 shows much higher identity/similarity to peroxisomal hAGT1 protein than 
to mitochondrial hAGT2, which has a different fold (Table 1). The sequence of AGXT-1 is

16413 residues longer than hAGT1 and all catalytic residues involved in the binding and 165 stabilization of the coenzyme at the active site are conserved in both proteins (Figure 1, 166 red highlighted residues) [24]. However, we also found two interesting differences between 167 the two primary sequences (Figure 1, green highlighted residues). First, the 13 extra 168 residues of $\mathrm{AGXT}-1$ protein are located in the $\mathrm{N}$-terminal domain. Mitochondrial targeting 169 sequences (MTS) usually consist of $20-60$ residues in the $\mathrm{N}$-terminal domain that are 170 prone to form an amphipathic alpha helix [25]. Bioinformatics tools, such as MitoProt [26] 171 or TargetP 1.1 Server [27], predict probabilities of $75-85 \%$ for the $\mathrm{N}$-terminal domain of 172 AGXT-1 to form a cleavable amphipathic alpha helix consistent with a potential MTS. 173 Second, the AGXT-1 protein lacks the C-terminal tripeptide that constitutes the 174 peroxisomal targeting sequence type 1 (PTS1) required for hAGT1 peroxisomal import 175 through Pex5p-dependent route [28,29], which is conserved between humans and 176 nematodes [30]. C. elegans also lacks the alternative PTS2 pathway to target proteins to 177 peroxisomes [31]. All together, these data suggest that AGXT-1 is not likely to be imported 178 to peroxisomes, in contrast to hAGT1 [2], but more likely to be imported to mitochondria.

Table 1. Identity and similarity in pairwise sequence alignments of AGXT-1, hAGT1 and hAGT2 proteins. Alignments were carried out using Clustal Omega [32]. GI numbers of protein sequences are: hAGT1-126522481, hAGT2-119576316 and AGXT-1-5824614.

\begin{tabular}{|l|l|l|l|}
\hline Residues & hAGT1 vs. hAGT2 & AGXT-1 vs. hAGT1 & AGXT-1 vs. hAGT2 \\
\hline Identical & $75(19 \%)$ & $167(41 \%)$ & $77(19 \%)$ \\
\hline Similar & $112(28 \%)$ & $121(30 \%)$ & $103(25 \%)$ \\
\hline
\end{tabular}




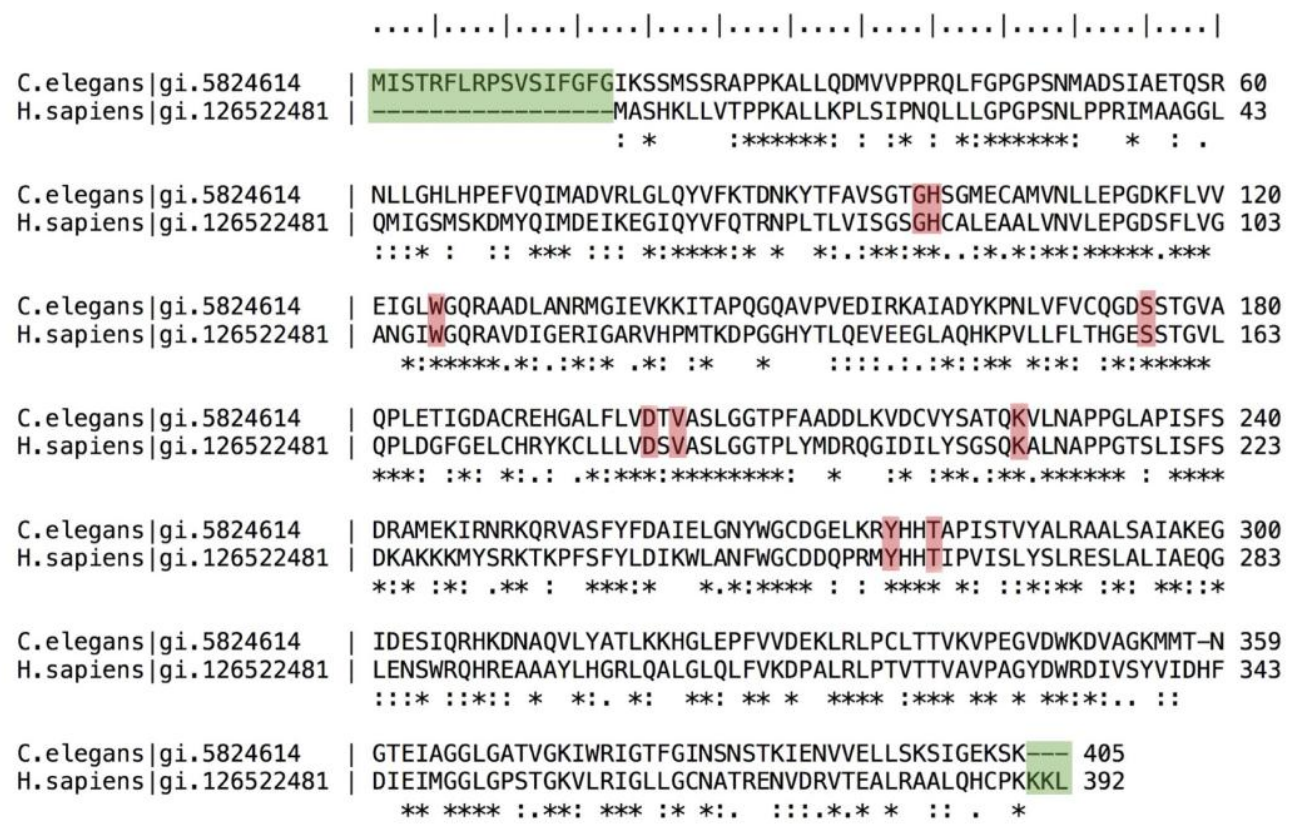

Figure 1. Protein sequence comparison between nematode AGXT-1 and human hAGT1 protein. AGXT-1 (Gl: 5824614) and hAGT1 (Gl: 126522481) protein sequence; identical residues are marked as $\left(^{*}\right)$, similar residues as (:), residues with similar shapes as (.) and gaps by (-); residues of the active site are highlighted in red, while gaps in both terminal domains are in green.

In order to confirm this hypothesis, we generated transgenic $C$. elegans strains expressing AGXT-1 fused to the N-terminus of tagRFP. Considering that previous studies have shown the in vivo promoter activity of the agxt-1 gene in muscle cells $[33,34]$ and the very distinctive mitochondrial tubular pattern of muscle cells $[35,36]$, our construct was expressed in body wall and vulval muscle cells under the control of the myo-3 promoter. Unfortunately, expression of the full AGXT-1 fused to tagRFP resulted in big clumps of fluorescence, reminiscent of aggregation and distorted mitochondria (data not shown). This could be a consequence of either a non-proper folding of tagRFP and/or the high 187 level of expression of the recombinant protein. To avoid this aggregation issue, we generated additional transgenic strains expressing only the fusion of the $\mathrm{N}$-terminal sequence of AGXT-1 (containing the putative MTS) with tagRFP. We generated two different transgenic strains expressing the first 50 and 100 amino acids of AGXT-1 fused in 191 frame with tagRFP. As mitochondrial marker, we used a transgenic strain expressing a 
TOMM-20::GFP fusion protein $[37,38]$. When tagRFP was expressed alone (Figure 2a), a

193 diffused cytosolic pattern was seen (Figure 2c), compared with the mitochondrial 194 localization of TOMM-20::GFP protein (Figure 2b). However, tagRFP fused to either the 195 first 50 or 100 amino acids of AGXT-1 (Figure 2e-i), was targeted to mitochondria (Figure $1962 \mathrm{~g}-\mathrm{k}$ ), as demonstrated by the colocalization with TOMM-20::GFP (Figure 2h-I). These 197 data confirm that the N-terminus of AGXT-1 encodes a functional MTS, thus reinforcing 198 the idea of AGXT-1 being a mitochondrial enzyme in C. elegans.

(a)

\begin{tabular}{|c|c|c|}
\hline myo-3 promoter & tagRFP & Unc-54 3'UTR \\
\hline
\end{tabular}

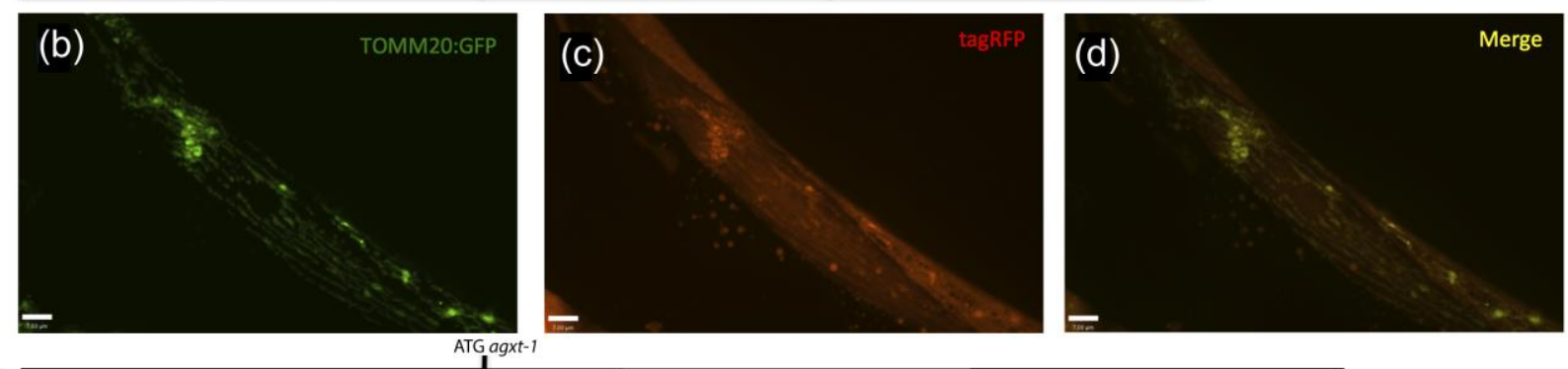

(e)
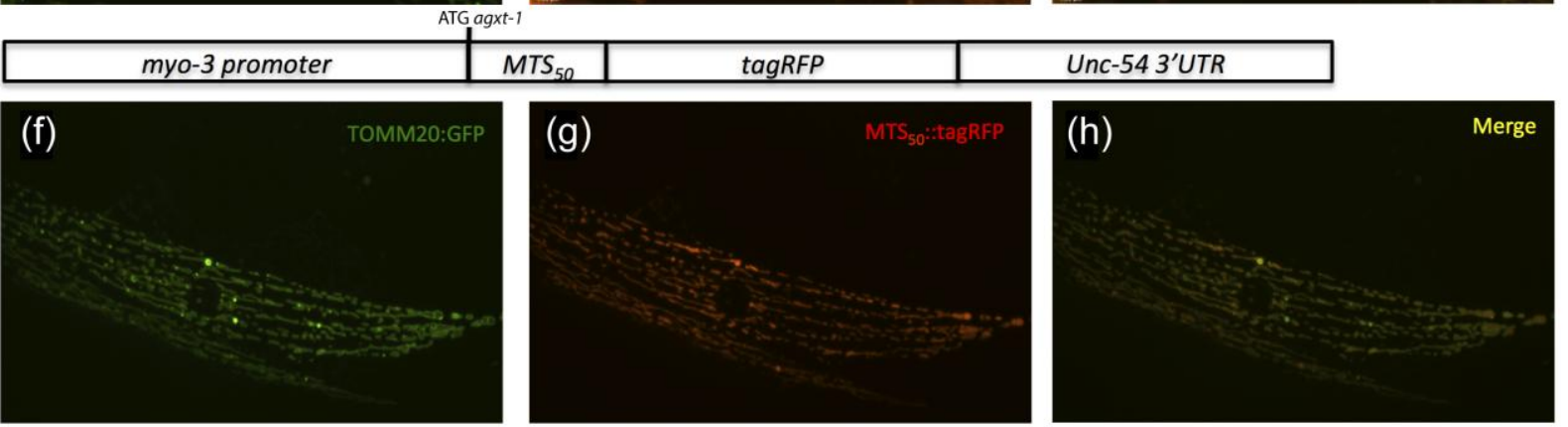

(i)

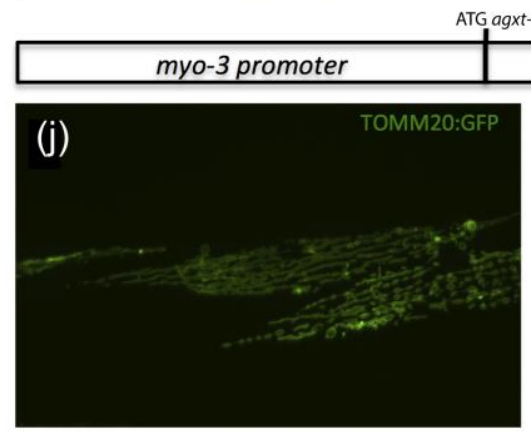

MTS $_{100}$

tagRFP

Unc-54 3'UTR
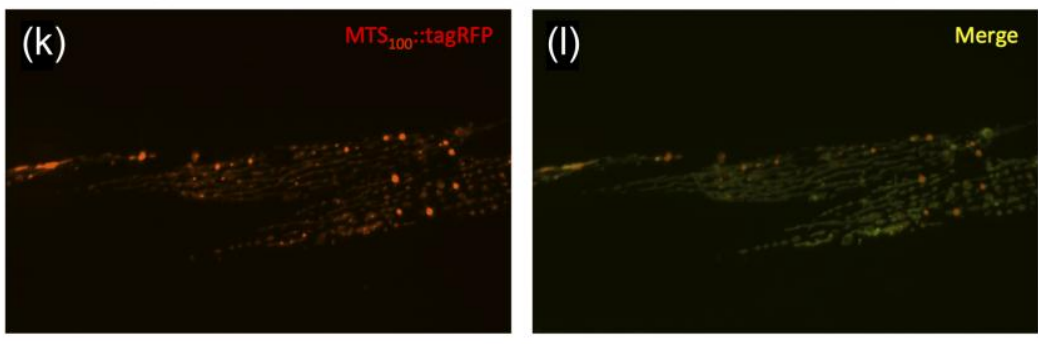
Figure 2. Mitochondrial localization of AGXT-1. Cartoons representing the DNA constructs used to express tagRFP (a), the first 50 amino acids (e) and the first 100 amino acids (i) of AGXT-1 fused to tagRFP under the control of the myo-3 promoter along with the unc-54 3'-UTR. TOMM-20::GFP expression is found with the typical tubular mitochondrial pattern in muscle cells $(b, f$ and $j)$. When tagRFP is expressed alone, a diffused cytosolic pattern is seen (c) and no colocalization is found with TOMM-20::GFP (d, merge). Fusing the first N-terminal $50\left(\mathrm{MTS}_{50}\right)(\mathrm{g})$ or $100\left(\mathrm{MTS}_{100}\right)(\mathrm{k})$ amino acids of the AGXT-1 to tagRFP targets the protein to mitochondria. The GFP and tagRFP fluorescence now colocalize to the same organelle ( $h$ and I, merge).

AGXT-1 and hAGT1 share overall structure. Taking into account the considerable sequence homology between AGXT-1 and hAGT1, we built a structural homology model of AGXT-1 using the available crystal structure of hAGT1 as a template [24]. Due to the high flexibility of the N-terminus of hAGT1 and substantial sequence differences between the N-terminal domains of both proteins (Figure 1), we did not include in the structural 204 alignment the first 38 and 23 amino acids of AGXT-1 and hAGT1, respectively. The AGXT2051 model was subsequently refined by energy minimization. The superposition of the 206 obtained AGXT-1 model and the hAGT1 structure predicts that the two proteins share a 207 similar overall conformation and secondary structure composition (Figure 3a). The binding 208 mode of PLP to AGXT-1 protein appears to be very similar to that of the human enzyme 209 and involves a Schiff base linkage with Lys226, a base stacking hydrophobic interaction 210 between the pyridine ring and the side chain of Trp125, a salt bridge between the $\mathrm{N} 1$ of 211 PLP and Asp200, an H-bond of the $3{ }^{\prime} \mathrm{OH}$ group of PLP and Ser175 and several H-bonds 212 between the phosphate group of the coenzyme and Gln225, Gly99 and His100 (Figure 213 3b). Moreover, two interchain contacts of the phosphate group of PLP in hAGT1 with 214 Tyr260 and Thr263 of the neighbouring subunit, are probably held by Tyr277 and Thr280 215 in AGXT-1. However, some differences are visible in the active site region and on the protein 217 surface. As for the active site cleft, Ser81 that in hAGT1 is critical for PLP binding [39] is 
218 replaced by a threonine residue (Thr98) in AGXT-1. Moreover, Arg360, whose side chain 219 binds the carboxylate group of the substrate in hAGT1 [24], is replaced by Ile377 in AGXT2201 (Figure 3c), thus leading to a different active site polarity and possibly a different 221 substrate binding mode. In addition, Trp246 and Met259 of hAGT1 are replaced by Glu263 222 and Arg276 in AGXT-1. As shown in Figure 3d, these two charged residues could interact 223 by a salt bridge, thus probably stabilizing the interface loop 276-282 comprising the 224 aforementioned Tyr277 and Thr280 residues involved in the binding of the coenzyme. 225 Electrostatic surface map calculations revealed that AGXT-1 would exhibit a higher density 226 and a different distribution of the surface charges with respect to hAGT1 (not shown).

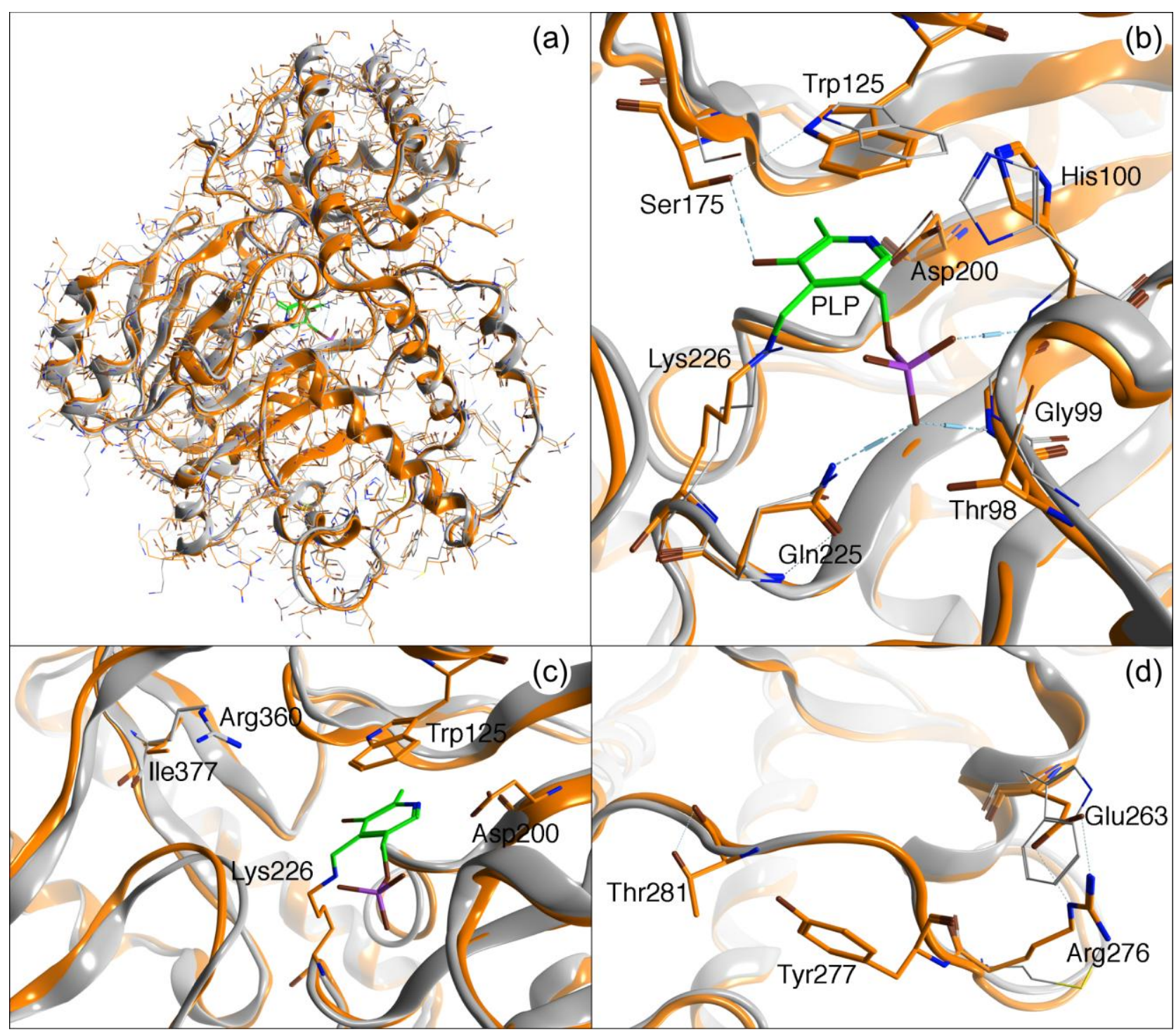


Figure 3. Structural alignment of the AGXT-1 model with the hAGT1 structure. Structural over imposition of AGXT-1 (orange) and hAGT1 (grey). The two backbones are represented as ribbons and the single residues as sticks. The PLP molecule is represented as green sticks.

AGXT-1 is a dimeric PLP-dependent alanine:glyoxylate aminotransferase. To compare the molecular properties of AGXT-1 and hAGT1, both recombinant proteins were expressed in and purified from E. coli. Along protein purification, size-exclusion chromatography analyses showed a single peak with similar retention volumes for both proteins and attributable to a dimer $\left(82.6 \mathrm{ml}\right.$ and $84.9 \mathrm{ml}$ in a Superdex ${ }^{\mathrm{TM}} 20016 / 60$ for hAGT1 and AGXT-1, respectively). Dynamic light scattering studies also revealed similar hydrodynamic diameters for both proteins $(8.1 \pm 0.1 \mathrm{~nm}$ vs. $8.8 \pm 0.4 \mathrm{~nm}$, for hAGT1 and AGXT-1, respectively), thus further confirming the dimeric assembly of the two proteins $[16,40]$. As isolated, both proteins show spectroscopic features corresponding to PLP bound to the active site by a Schiff base with Lys209 in hAGT1 and Lys226 in AGXT-1. The UV-visible absorption and CD spectra of AGXT-1 display a band at $430 \mathrm{~nm}$, which likely reflects the ketoenamine tautomer of the internal Schiff base, and a band at $340 \mathrm{~nm}$, possibly corresponding to enolimine tautomer (Figure 4 and [6]). After incubation of AGXT-

2401 with L-alanine, the spectra show almost no signal at $430 \mathrm{~nm}$ and a main absorption peak 241 and weak dichroic band at $340 \mathrm{~nm}$ (Figure 4). These signals indicate the formation of the pyridoxamine-5'-phosphate (PMP) form of the coenzyme, thus supporting the proper

243 binding of PLP in the active site of AGXT-1 to take the amino group from the substrate L244 alanine. Attempts to remove the coenzyme from the active site of AGXT-1 (to obtain the 245 apo-form) by using the procedure applied for hAGT1 [16,17] yielded a form of AGXT-1 246 with PMP tightly bound, suggesting a very high affinity and/or very slow dissociation rate of 247 PMP. Further reduction of the $\mathrm{pH}$ (below 5.8) resulted in irreversible denaturation of 248 AGXT-1 before the release of the coenzyme, thus preventing a comparison between the 
apo-form of AGXT-1 and hAGT1. Together, these results suggest that AGXT-1 binds PMP 250 with higher affinity than hAGT1 and/or that the $\mathrm{pH}$ value for efficient PMP release is lower 251 for AGXT-1.

Next, the ability of AGXT-1 to catalyse the amino transfer by using the natural 253 substrates of hAGT1 (L-alanine and glyoxylate) was tested (Figure 5). Activity data were 254 analysed by using a coupled enzyme assay as described for hAGT1 [6,16]. Kinetic 255 parameters for the overall transamination show that AGXT-1 has 5 -fold higher activity $256\left(\mathrm{~V}_{\max }\right)$ than hAGT1 (Table 2), while apparent affinities $\left(\mathrm{K}_{\mathrm{M}}\right)$ for both substrates are kept in 257 similar ranges. Only the apparent affinity for L-alanine is slightly higher (1.6-fold higher) for 258 AGXT-1 than for hAGT1. These results support a higher catalytic efficiency towards 259 glyoxylate for the nematode enzyme than for the hAGT1. In addition, both proteins show 260 similar dependence of the overall transaminase activity on temperature and pH (Figure 6). 261 Arrhenius analyses of temperature dependence of transaminase activity reveal an 262 activation energy value of $4.0 \pm 0.9 \mathrm{kcal} \cdot \mathrm{mol}^{-1}$ for $A G X T-1$, somewhat higher than for 263 hAGT1 $\left(2.2 \pm 1.8 \mathrm{kcal} \cdot \mathrm{mol}^{-1}\right)($ Figure $6 \mathrm{a})$. The activity of both enzymes decreases at mild 264 acidic $\mathrm{pH}$ (Figure 6b-c), suggesting similar pattern of protonation states of the active site of 265 both proteins, which could be a sign of similar reaction specificities [41] and environmental $266 \mathrm{pH}$ in their intracellular localization [42]. 

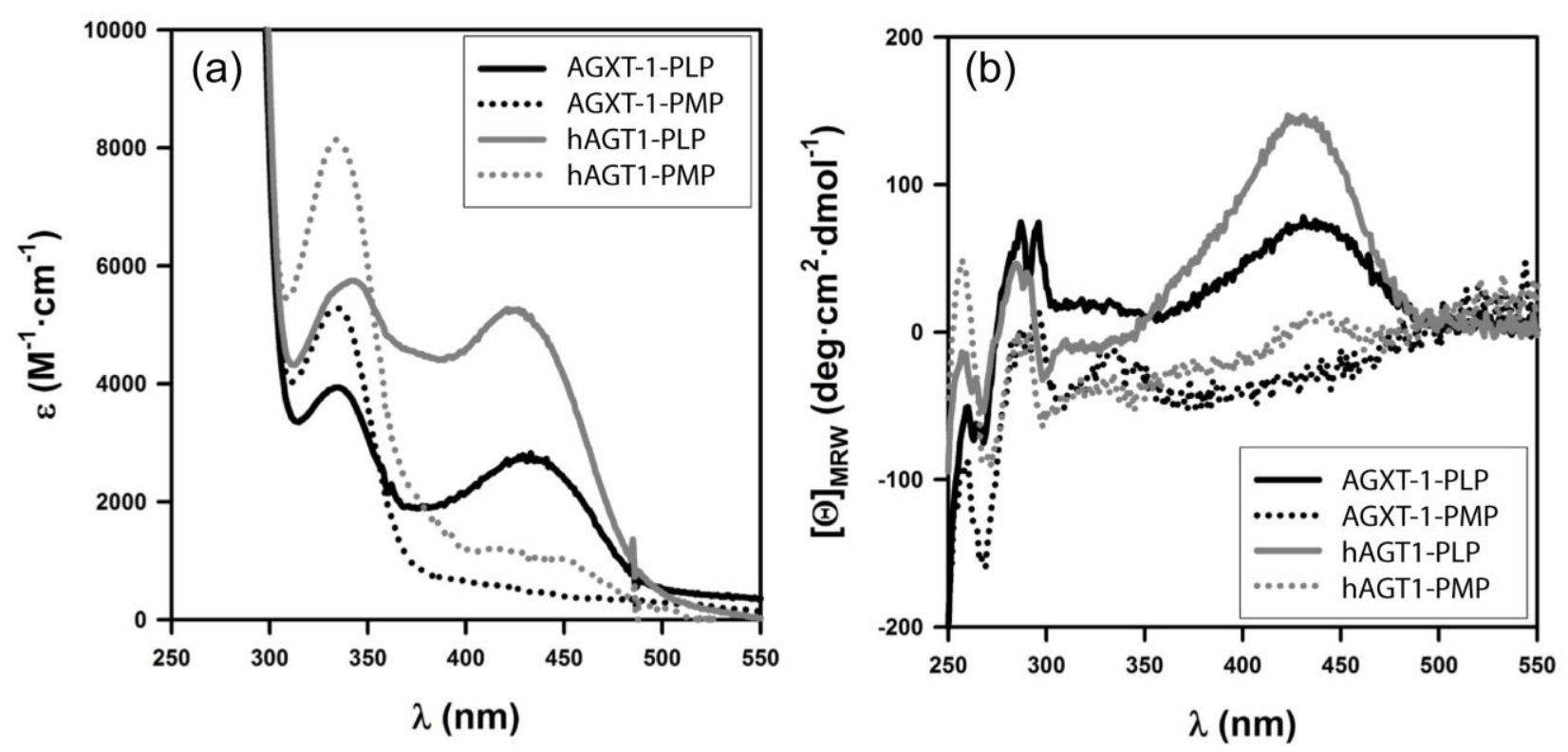

Figure 4. Near-UV/visible spectroscopic analyses of AGXT-1 and hAGT1 in their PLPbound forms and in the presence of $0.5 \mathrm{M}$ L-alanine (PMP-forms). (a) Near-UV/visible absorption spectra; (b) Near UV/visible circular dichroism spectra; Protein concentration was $20 \mu \mathrm{M}$ in monomer.

Table 2. Kinetic parameters of the overall transaminase activity for AGXT-1 and hAGT1. Data are mean \pm s.d. from global fits from a coupled enzyme assay.

\begin{tabular}{|l|l|l|}
\hline Parameter & AGXT-1 & hAGT1 \\
\hline $\mathrm{V}_{\max }\left(\mathrm{mmol} \cdot \mathrm{h}^{-1} \cdot \mathrm{mg}^{-1}\right)$ & $11.3 \pm 0.7$ & $2.2 \pm 0.1$ \\
\hline $\mathrm{K}_{\mathrm{M}, \text { alanine }}(\mathrm{mM})$ & $12 \pm 2$ & $20 \pm 2$ \\
\hline $\mathrm{K}_{\mathrm{M}, \text { glyoxylate }}(\mathrm{mM})$ & $0.26 \pm 0.05$ & $0.26 \pm 0.04$ \\
\hline
\end{tabular}



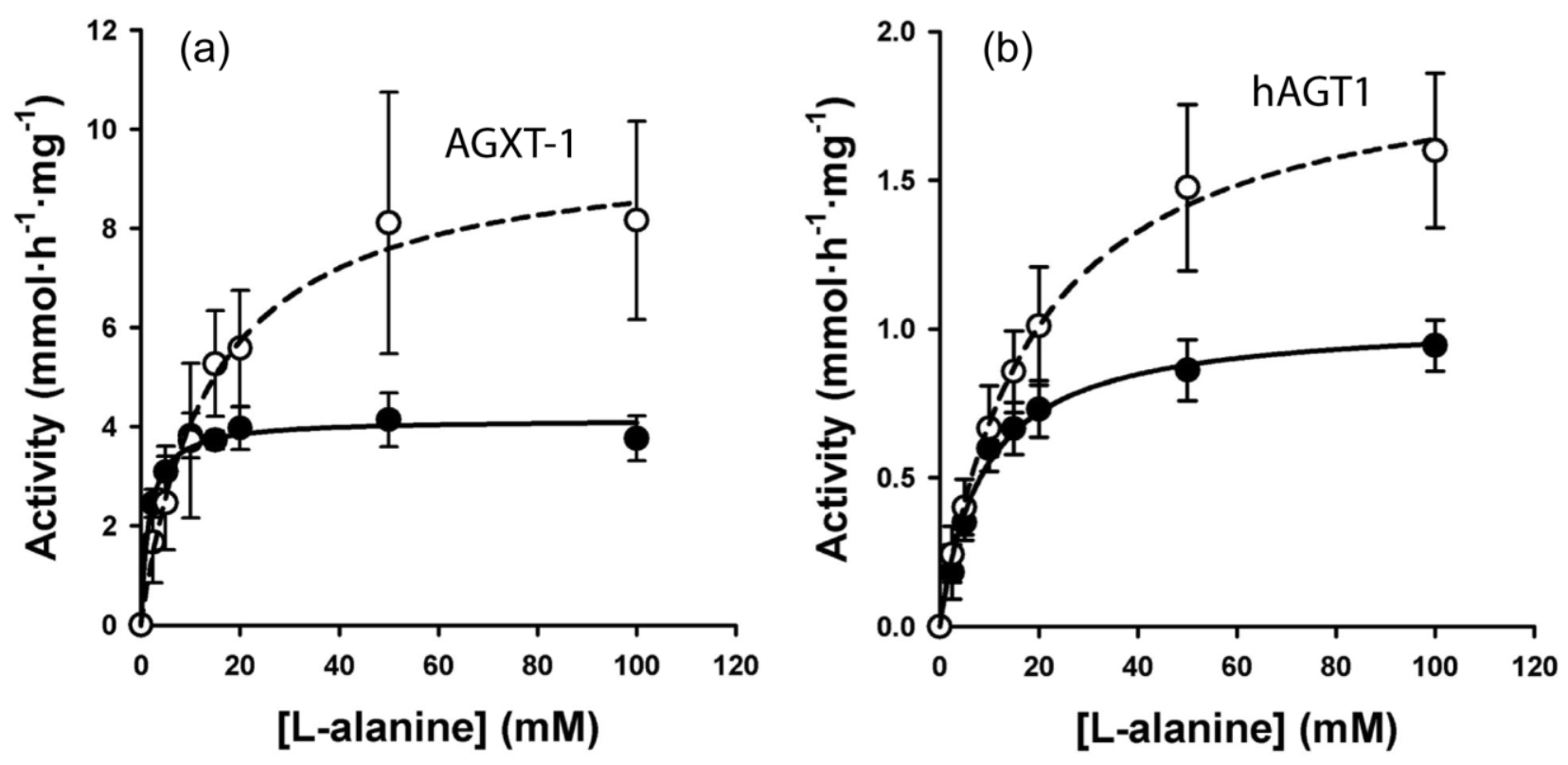

Figure 5. Enzyme kinetic analyses of AGXT-1 (a) and hAGT1 (b) proteins in the presence of L-alanine and glyoxylate. Experiments were performed at $0.25 \mathrm{mM}$ (closed circles) and $2 \mathrm{mM}$ (open circles) glyoxylate and varying $\mathrm{L}$-alanine concentrations. Lines are global best-fits to an enzyme-substituted kinetic mechanism yielding the kinetic parameters shown in Table 2.

The large difference in activity between AGXT-1 and hAGT1 towards the alanine:glyoxylate pair prompted us to investigate whether these two enzymes may share similar substrate specificity [6] . To this aim, we determined the specific activity of these enzymes by using glyoxylate or pyruvate as amino acceptors and different natural L-amino

271 acids as amino donors (Figure 7). When using glyoxylate as amino acceptor, AGXT-1 272 protein is very specific towards L-alanine showing 300 -fold and 130 -fold higher activity 273 than for L-serine and L-phenylalanine and no detectable activity towards L-arginine, L274 glutamate and L-aspartate (Figure 7a). Under similar conditions, hAGT1 is somewhat less specific, with 23-fold and 52-fold lower activity towards L-serine and L-arginine and 100fold and 200-fold lower activity towards L-phenylalanine and L-glutamate (Figure 7a). 277 Using pyruvate as amino acceptor (Figure 7b), both enzymes display lower activity 278 towards L-serine than those measured using glyoxylate. Their activities towards L- 
279 phenylalanine are comparable, L-arginine is a better substrate for hAGT1 than AGXT-1 280 and L-glutamate and L-aspartate are poor substrates for both enzymes. Even though 281 some differences exist, these studies support similar substrate specificities for both 282 proteins and demonstrate that AGXT-1 protein is an alanine:glyoxylate aminotransferase.
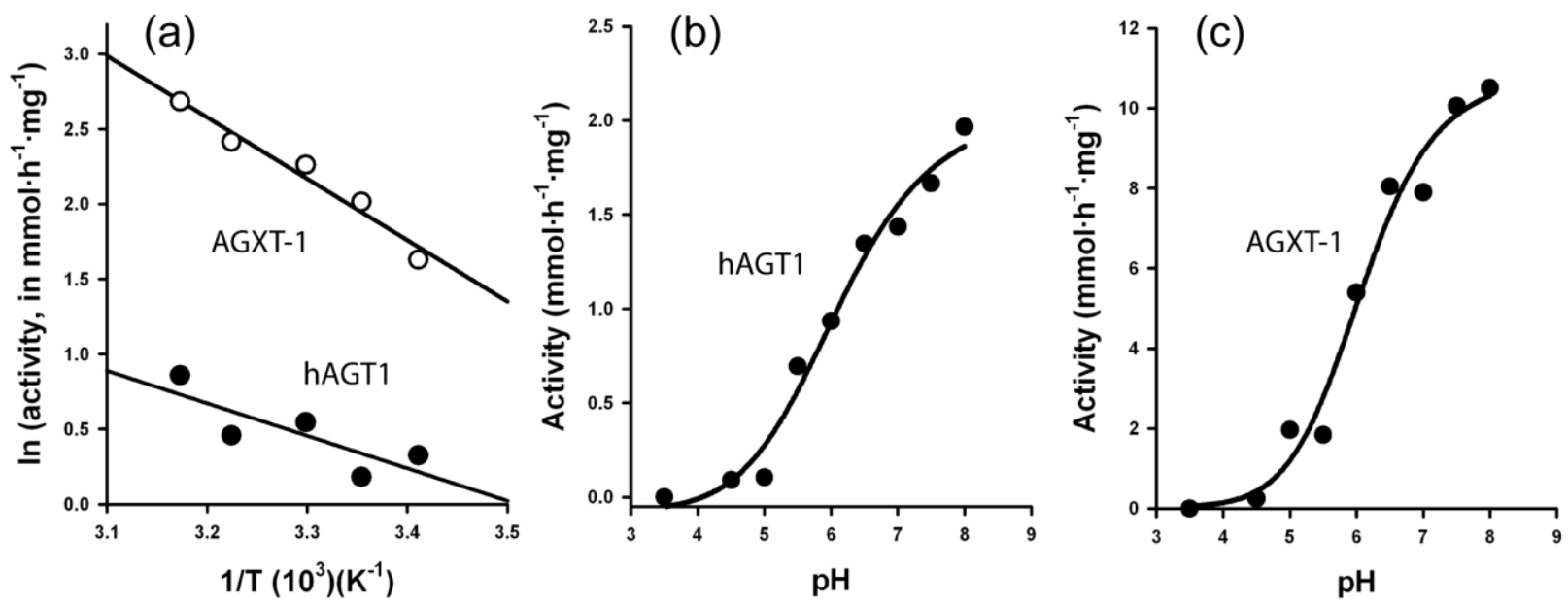

Figure 6. Temperature- and pH-dependence of the overall transaminase activity for AGXT-1 and hAGT1 proteins. (a) Arrhenius plots for the enzymatic activity of AGXT-1 and hAGT1; (b) and (c) pH-dependence of the enzymatic activity of hAGT1 and AGXT-1, respectively. Activity was measured in the presence of $100 \mathrm{mM}$ L-alanine and $2 \mathrm{mM}$ glyoxylate. 
(a)

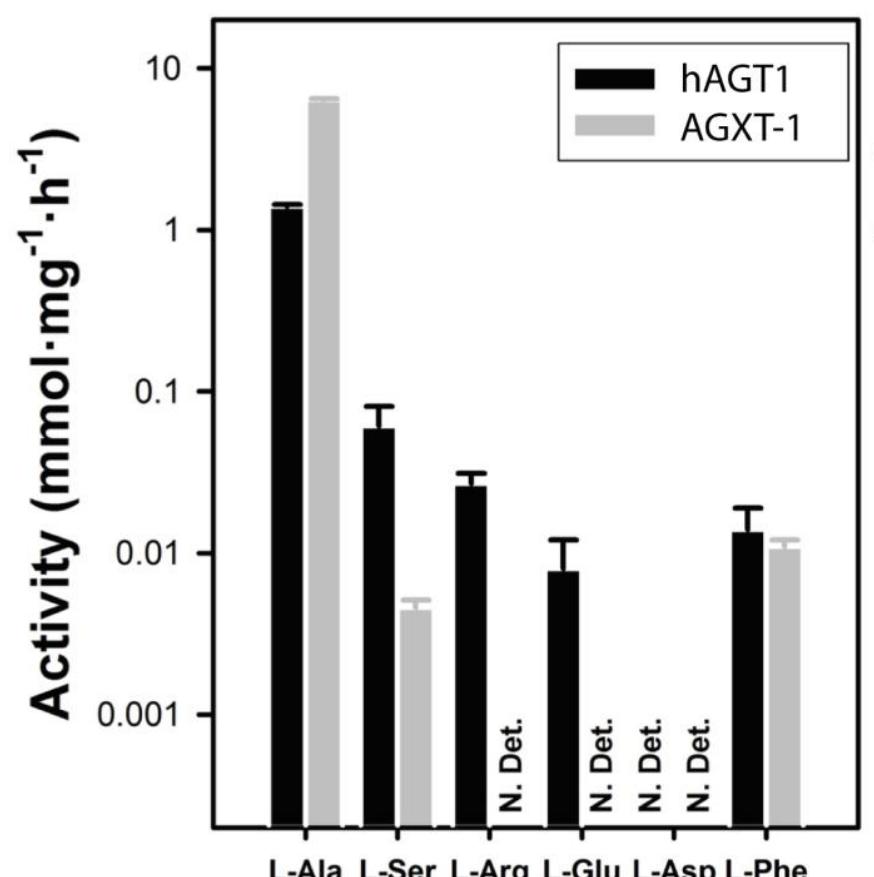

L-Ala L-Ser L-Arg L-Glu L-Asp L-Phe

Amino donor (b)

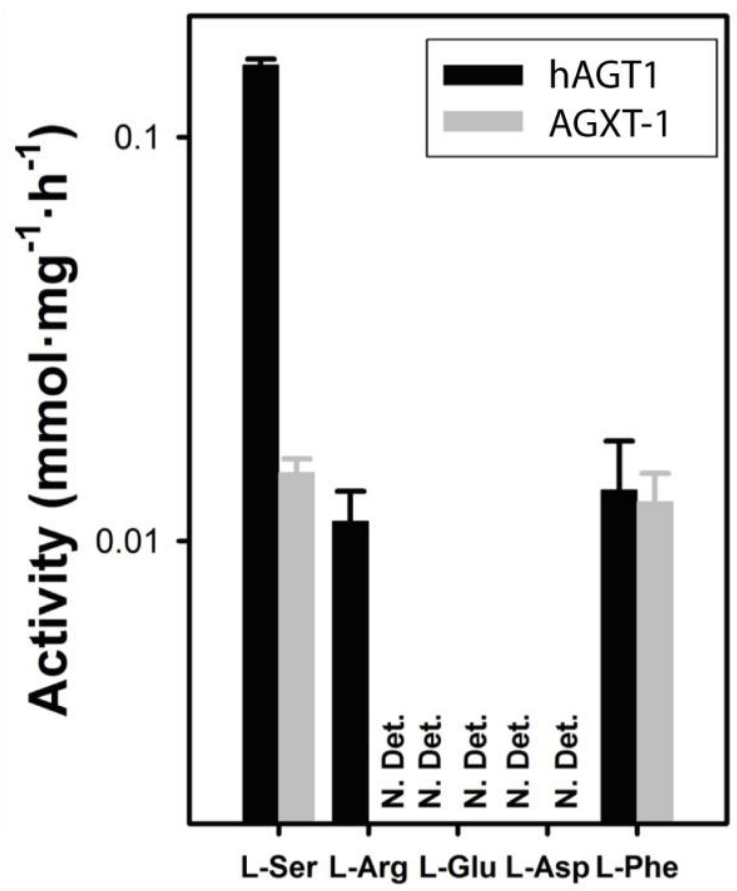

Amino donor

AGXT-1 shows lower resistance towards thermal and chemical denaturation.

284 Thermal denaturation of AGXT-1 was studied by differential scanning calorimetry (DSC).

285 Both AGXT-1 and hAGT1 show a single denaturation transition (Figure 8a), which is well 286 described by a simple two-state irreversible denaturation model with first-order kinetics 287 (supported by protein concentration independent denaturation transitions $[16,17]$ and data 288 not shown). The denaturation temperature $\left(T_{m}\right)$ of $A G X T-1$ is about $12^{\circ} \mathrm{C}$ lower than that of 289 hAGT1 (Table 3). The lower denaturation enthalpy $(\Delta \mathrm{H})$ of AGXT-1 seems to be a 290 consequence of the lower thermal stability of this protein and a strongly temperature 291 dependent $\Delta \mathrm{H}$ with a theoretical denaturation heat capacity of about $11 \mathrm{kcal} \cdot \mathrm{mol}^{-1} \cdot \mathrm{K}^{-1}$ 
292 (based on the correlations by [43]), thus suggesting that the amount of tertiary structure 293 lost upon thermal denaturation in both enzymes is fairly similar. Due to the kinetic control 294 of thermal denaturation for both enzymes, the DSC analyses can be used to extrapolate 295 the denaturation rate constants to physiological temperatures (inset Figure 8a). The 296 extrapolated kinetic stability for AGXT-1 towards thermal denaturation at $37^{\circ} \mathrm{C}$ is around 297 200-fold lower than hAGT1 at this temperature (Table 3). However, when we compare the 298 kinetic stability of both proteins at the corresponding physiological temperature $\left(37^{\circ} \mathrm{C}\right.$ for 299 hAGT1 and $20^{\circ} \mathrm{C}$ for AGXT-1) the nematode protein is 90 -fold more stable than hAGT1.

Table 3. Thermal denaturation parameters for AGXT-1 and hAGT1. The parameters have been determined from DSC scans using a two-state irreversible denaturation model. 1 Data from Mesa-Torres, PLoS One, 2013. ${ }^{2}$ Determined at $3^{\circ} \mathrm{C} \cdot \mathrm{min}^{-1}$ scan rate. ${ }^{3}$ mean \pm s.d. from three different scan rates. ${ }^{4}$ kinetic constant rates for irreversible denaturation extrapolated to $37^{\circ} \mathrm{C}\left(20^{\circ} \mathrm{C}\right)$

\begin{tabular}{|l|l|l|}
\hline Parameter & AGXT-1 & hAGT1 $^{1}$ \\
\hline $\mathrm{T}_{\mathrm{m}}\left({ }^{\circ} \mathrm{C}\right)^{2}$ & 69.8 & 82.1 \\
\hline$\Delta \mathrm{H}\left(\mathrm{kcal} \cdot \mathrm{mol}^{-1}\right)^{3}$ & $366 \pm 11$ & $548 \pm 5$ \\
\hline $\mathrm{E}_{\mathrm{a}}\left(\mathrm{kcal} \cdot \mathrm{mol}^{-1}\right)^{3}$ & $112 \pm 15$ & $109 \pm 5$ \\
\hline$k_{37^{\circ} \mathrm{C}}\left(\mathrm{k}_{20^{\circ} \mathrm{C}}\right)\left(\mathrm{min}^{-1}\right)^{4}$ & $1.2 \cdot 10^{-7}\left(7.1 \cdot 10^{-12}\right)$ & $6.4 \cdot 10^{-10}$ \\
\hline
\end{tabular}

Urea induced denaturation of AGXT-1 was investigated by Far-UV circular 301 dichroism spectroscopy (Figure 8b). Denaturation profiles of AGXT-1 and hAGT1 show a 302 single transition and once again, AGXT-1 displays a lower stability with half-denaturation 303 urea concentration of $\sim 3.8 \mathrm{M}(\mathrm{AGXT}-1)$ vs. $\sim 6 \mathrm{M}$ (hAGT1). The cooperativity of urea304 induced unfolding is apparently higher for AGXT-1 than for hAGT1. In contrast to hAGT1 305 ([44] and data not shown), urea unfolding of AGXT-1 is highly reversible (Figure 8b 306 squares). This reversibility suggests that, upon chemical denaturation, the refolding 307 pathway of AGXT-1 populates less aggregation-prone intermediate states. 


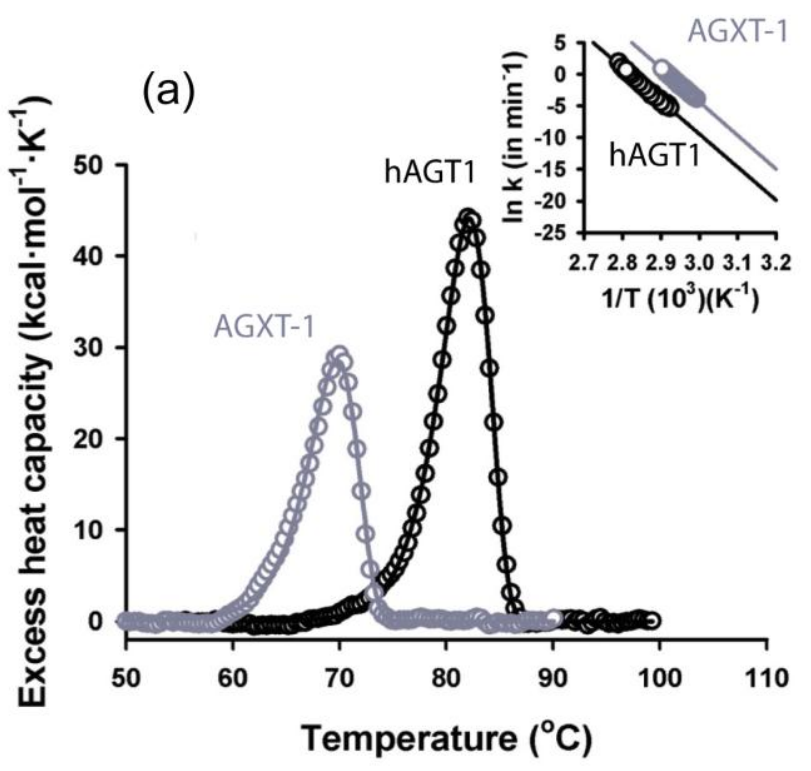

(b)

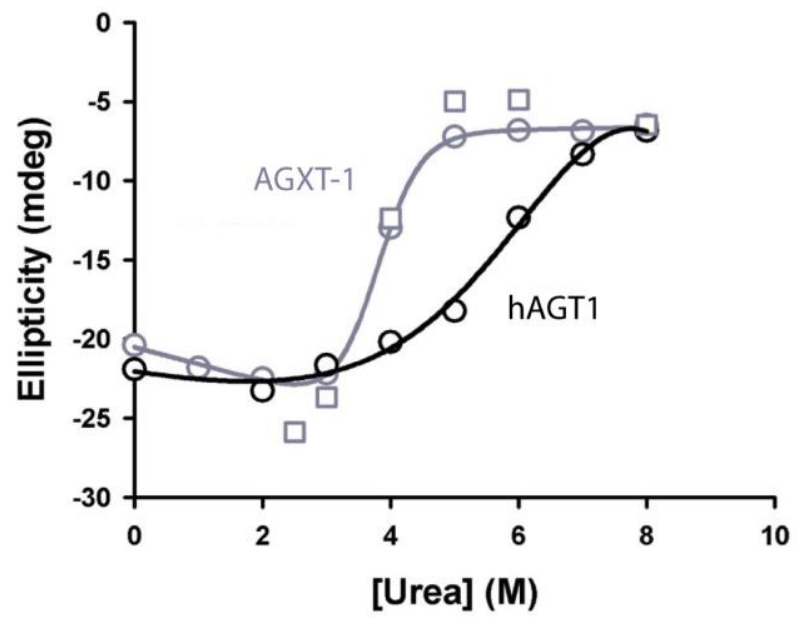

Figure 8. Stability of AGXT-1 and hAGT1 proteins towards thermal and chemical denaturation. (a) Thermal denaturation profiles of holo AGXT-1 and hAGT1 at $3^{\circ} \mathrm{C} \cdot \mathrm{min}^{-1}$ and $5 \mu \mathrm{M}$ protein subunit in $20 \mathrm{mM} \mathrm{Na-Hepes,} 200 \mathrm{mM} \mathrm{NaCl} \mathrm{pH} \mathrm{7.4.} \mathrm{Lines} \mathrm{are} \mathrm{best-fits} \mathrm{to}$ a two-state irreversible model with first-order kinetics; Inset: Arrhenius plots for thermal denaturation kinetics; (b) Urea-induced unfolding of holo AGXT-1 and hAGT1 at $5 \mu \mathrm{M}$ protein subunit in $20 \mathrm{mM}$ Na-Hepes, $200 \mathrm{mM} \mathrm{NaCl} \mathrm{pH} \mathrm{7.4,1} \mathrm{mM}$ TCEP at 25ㄷ․ Circles show the results for unfolding, while squares correspond to refolding experiments.

\section{Discussion}

Glyoxylate is a metabolic intermediary in humans that has to be detoxified mainly by hAGT1 in peroxisomes [2]. Instead, glyoxylate is a key metabolite in $C$. elegans due to the

311 presence of an active glyoxylate cycle [10,12]. The sequencing of $C$. elegans genome predicted a putative ortholog of human AGXT gene in the nematode (ORF T14D7.1, [9] now renamed to agxt-1 ). However, the molecular properties of the protein product of agxt-1 gene have not been previously investigated. Here, we have performed a side-byside comparative study on the molecular properties of AGXT-1 protein in comparison with

316 human hAGT1, showing that AGXT-1 is a functional PLP-dependent enzyme with 317 aminotransferase activity and a higher activity and specificity towards the 318 alanine:glyxoxylate pair than hAGT1. Our results also support that both enzymes are 
319 structurally and functionally alike, but show different protein stability and subcellular localization, where AGXT-1 is mitochondrial and hAGT1 is peroxisomal.

The mitochondrial localization of AGXT-1 provides important insights into the evolutionary adaptation of AGTs subcellular compartmentalization, and possibly, into its relation with dietary origins of glyoxylate and the molecular origin of mitochondrial mistargeting in PH1. AGT subcellular localization has represented a remarkable conundrum for cell and evolutionary biologists and molecular pathologists. The AGTs peroxisomal localization is attributed to a PTS1 located at the C-terminal domain, while the mitochondrial localization is mainly controlled by the activation of a cryptic MTS in the Nterminal domain that overrides the PTS1 route [1]. Therefore, the AGXT gene seems to have evolved to meet dietary requirements, with alternative translation and transcription sites to allow the protein to contain this strong MTS sequence [45]. In most omnivorous mammals the AGT enzyme is distributed in mitochondria or peroxisomes, based on the presence or absence of the MTS, respectively. In carnivorous mammals, the AGT localization is mainly mitochondrial while a selective loss of the MTS is found in 334 herbivorous animals [46]. These evolutionary changes in subcellular distribution of AGT 335 associated with dietary changes have been recently exemplified by sequencing and evolutionary analyses on different bat species with unparalleled dietary diversification [47]. Importantly, hAGT1 contains a very weak MTS, which becomes stronger in the presence 338 of the destabilizing $\mathrm{P} 11 \mathrm{~L}$ polymorphism and certain pathogenic mutations, that result into 339 mitochondrial mistargeting $[16,48]$. Unlike the behaviour found along evolution, which 340 seems to define the subcellular targeting of AGT using relatively simple transcriptional and 341 translational mechanisms, mitochondrial mistargeting of hAGT1 seems to depend strongly 342 on the cellular context. For instance, a given single genotype may lead or not to 343 mitochondrial import depending on the cell type and culture conditions $[16,49,50]$ 
344 highlighting the important role of molecular chaperones and/or other factors of the protein 345 homeostasis network in the final fate of hAGT1 disease-causing variants $[16,17]$.

Along evolution, enzyme properties are selected to provide appropriate metabolic 347 rates at different physiological temperatures by tuning some structure-function 348 relationships i.e., stability, enzyme activity and ligand affinity [51]. While the physiological 349 temperature of humans is kept constant at $37^{\circ} \mathrm{C}$, the nematode $C$. elegans is an ectotherm 350 organism that can survive between $8-27^{\circ} \mathrm{C}$ and whose physiology is highly affected by the 351 environmental temperature. The lower denaturation temperature and high catalytic activity 352 of AGXT-1 likely reflects temperature-adaptation [52]. Moreover, the similar apparent 353 affinities for natural substrates of hAGT1 displayed by AGXT-1, suggest resemblance in 354 substrate concentration or $\mathrm{K}_{\mathrm{M}}:[$ [ubstrate] ratio, at their respective organelles [53] . It must 355 be noted that the activity and intracellular turnover of hAGT1 must be tuned to be 356 appropriate at a customarily constant temperature of $37^{\circ} \mathrm{C}$, while the conformational 357 stability of AGXT-1 seems to be adapted to lower temperatures. These results may 358 indicate that the overall stability of different AGT orthologs is optimized to provide an 359 adequate intracellular turnover at optimal growth temperature, which in the case of hAGT1 360 is severely compromised by disease-associated mutations leading to protein misfolding 361 and mistargeting $[2,16,40,54]$.

The main biological function of hAGT1 is to create a glyoxylate sink in peroxisomes 363 of hepatocytes. In addition, there is a set of proteins that contribute to this human 364 glyoxylate metabolism. According to KEGG (Kyoto Encyclopedia of Genes and Genomes) 365 and REACTOME Pathway Database, these proteins are D-amino acid oxidase (hDAO), 366 hydroxyacid oxidase (hHAO), glyoxylate reductase / hydroxypyruvate reductase 367 (hGRHPR), D-4-hydroxy-2-oxoglutarate aldolase (hHOGA1), alanine:glyoxylate 368 aminotransferase 2 (hAGT2) and lactate dehydrogenase (hLDH) (Figure 9). Despite the 
369 key role of glyoxylate cycle in C. elegans [55] (Figure 9), surprisingly the genome of the 370 nematode encodes orthologous proteins to those already described for the human 371 glyoxylate metabolism, with the only exception of mitochondrial hHOGA1 protein (Table 4). 372 Therefore the main routes of glyoxylate metabolism in humans are expected to work in the 373 nematode, at least to some extent. Some phenotypes have been described by large-scale 374 gene downregulation in $C$. elegans, such as the association of C31C9.2 (ortholog of 375 hGRHPR) [9] with low embryonic lethality [56] and slow growing [57], or T09B4.8 376 (ortholog of hAGT2) linked to a reduction of fat content [58]. However, according to the 377 WormBase Consortium (www.wormbase.org - WS249) no altered lethality, fertility or 378 development has been described to the lack of function of AGXT-1, F41E6.5 (ortholog of $379 \mathrm{hDAO}), \mathrm{DAAO} 1$ and $\mathrm{LDH}-1$ proteins. This suggests that the steps of glyoxylate 380 metabolism that are catalysed by these enzymes may not be essential for the normal 381 development and metabolism of the nematode. Nonetheless, the relative contributions of 382 these enzymes to different biochemical pathways requires knowledge on their enzymatic 383 properties and regulation, expression levels and metabolic fluxes, which can be 384 developmental and environmental dependent [59]. Alternatively, there are no orthologous 385 proteins in humans to the key $C$. elegans enzyme ICL-1, although a human malate 386 synthase activity has been detected with unknown biological function [60]. 


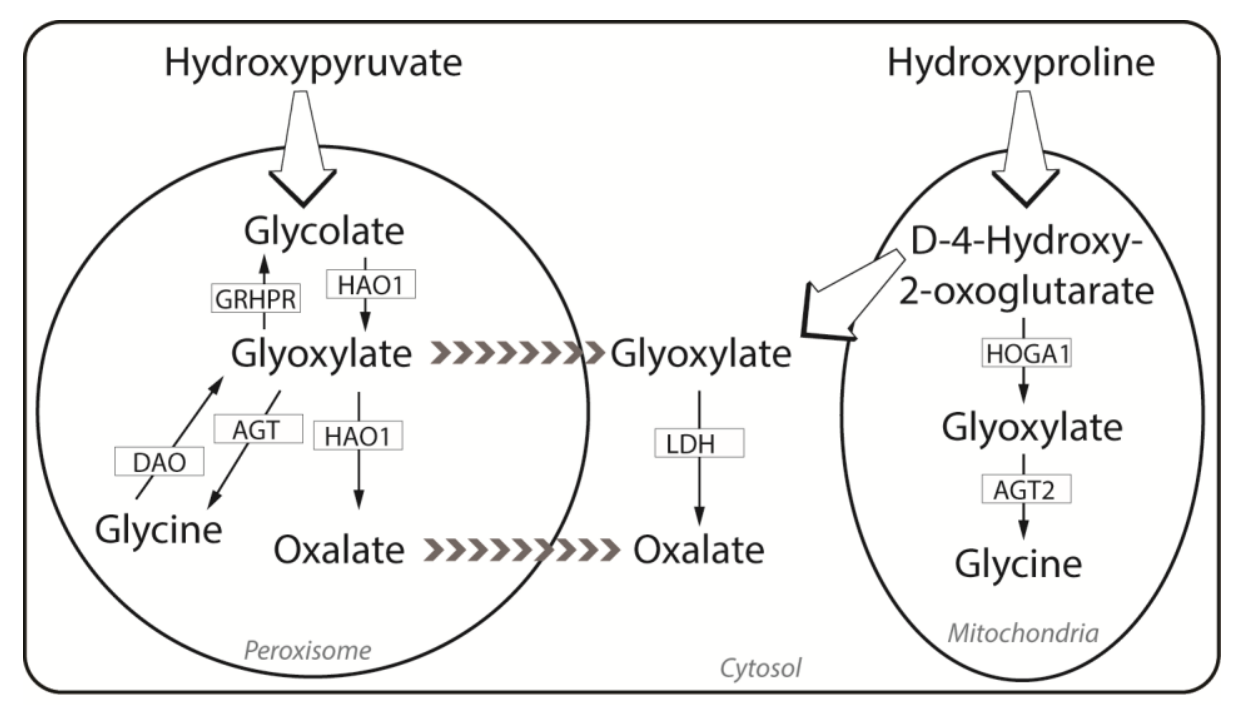

Human Hepatocyte

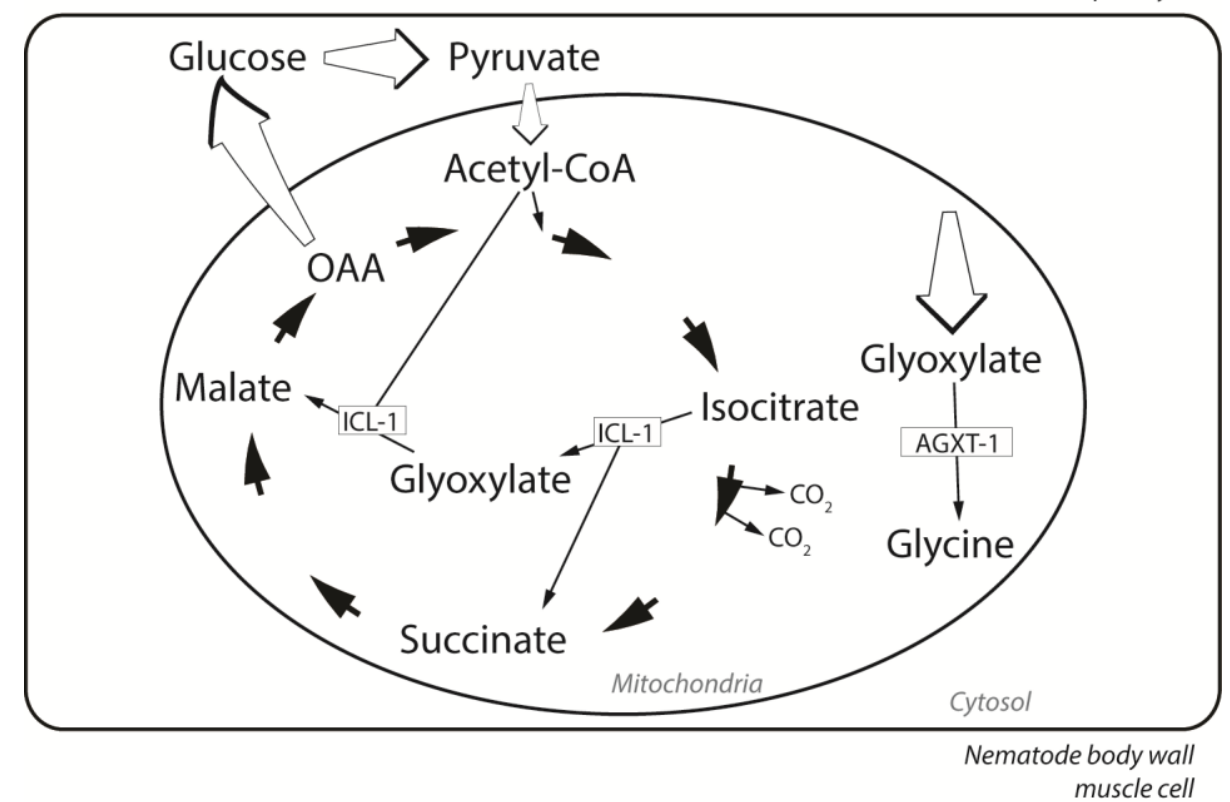

Figure 9. Main routes of glyoxylate metabolism in human hepatocytes and nematode body wall muscle cells. AGT: alanine:glyoxylate aminotransferase, DAO: D-amino acid oxidase, HAO1: hydroxyacid oxidase, GRHPR: glyoxylate reductase / hydroxypyruvate reductase, HOGA1: D-4-hydroxy-2-oxoglutarate aldolase, AGT2: alanine:glyoxylate aminotransferase 2, LDH: lactate dehydrogenase and ICL-1: bi-functional isocitrate lyase:malate synthase.

387 In $C$. elegans, GC bypasses the decarboxylation steps of TCA cycle supplying a net 388 synthesis of 4-carbon compounds and thus supporting gluconeogenesis by incorporating 389 acetyl-CoA (particularly from B-oxidation of fatty acids in peroxisome and mitochondria) 390 and supplying succinate to TCA cycle and malate to the gluconeogenesis pathway $[13,14]$. 
391 The GC activity is increased during embryogenesis, L1 larvae and dauer diapause, while 392 TCA cycle is increased in the L2, L3 and L4 stages, when energy demands and food 393 intake are increased [14]. The GC and TCA cycles share some enzymatic activities 394 (malate dehydrogenase, citrate synthase and aconitase), while some enzymes, ICL-1 395 (GC) and isocitrate dehydrogenase (TCA), compete for the same substrate (isocitrate). 396 Therefore the relative activity of these enzymes controls the ratio carbon flux through both 397 cycles (GC and TCA) [55]. Historically, unlike other nematodes [61], key enzymes of GC in 398 C. elegans have been considered to be compartmentalized in glyoxysome-like 399 microbodies by being found in a heavier band (apart from mitochondrial markers) in 400 isopycnic centrifugation [62] . However, it has been recently demonstrated that C-terminal 401 GFP tagged ICL-1 protein co-localizes with mitochondrial dye MitoTracker [63]. This 402 preview notion of a physical separation between GC and TCA enzymes implied either the 403 existence of isoforms of those shared enzymes activities in glyoxysomes or the 404 transportation of metabolites (e.g., isocitrate and succinate) across organelles membranes 405 [64], which was hypothesized to function as a metabolic regulatory mechanism [65]. The 406 existence of a mitochondrial alanine:glyoxylate aminotransferase (AGXT-1) and ICL-1 407 activities may imply a direct competition of both proteins for glyoxylate as substrate that 408 may participate in carbon flux through TCA and GC cycle pathways. The transamination of 409 glyoxylate into glycine by AGXT-1 could provide an alternative pathway for glyoxylate 410 conversion and also an additional way to modulate levels of glyoxylate in mitochondria, 411 which would otherwise be toxic and may affect the regulation of the TCA cycle by inhibiting 412 enzymes such as ketoglutarate dehydrogenase [66]. In humans, the hAGT1 activity is 413 known to act in the detoxification of glyoxylate within peroxisomes of hepatocytes, while 414 the presence of an active glyoxylate cycle in the nematode opens the possibility of 415 alternative metabolic roles for the AGXT-1 protein. To further characterize the role of 
416 AGXT-1 on different metabolic pathways and developmental conditions, a detailed

417 analysis of metabolites in cultures of $i c l-1$ and agxt-1 mutants should be approached.

Table 4. Orthologous proteins in $\boldsymbol{C}$. elegans found from a BLASTP of human proteins involved in glyoxylate metabolism. Gl numbers of protein sequence used are: hAGT- 126522481; hDAO- 148539837; hHAO- 11068137; hGRHPR- 6912396; hHOGA31543060; hAGT2- 119576316; hLDH- 32693754. n/a, not available.

\begin{tabular}{|c|c|c|c|c|c|c|}
\hline \multicolumn{3}{|c|}{ H. sapiens } & \multicolumn{4}{|c|}{ C. elegans } \\
\hline Protein & Residues & Localization & Protein & Residues & Identity & E value \\
\hline hAGT & 392 & Perox. & AGXT-1 & 405 & $44 \%$ & $5 \cdot 10^{-115}$ \\
\hline hDAO & 347 & Perox. & DAAO1 & 322 & $35 \%$ & $8 \cdot 10^{-61}$ \\
\hline $\mathrm{hHAO}$ & 370 & Perox. & F41E6.5b & 371 & $46 \%$ & $6 \cdot 10^{-115}$ \\
\hline hGRHPR & 328 & Perox./Cyt. & C31C9.2 & 322 & $30 \%$ & $1 \cdot 10^{-29}$ \\
\hline hHOGA & 327 & Mito. & Not found & $\mathrm{n} / \mathrm{a}$ & $\mathrm{n} / \mathrm{a}$ & $\mathrm{n} / \mathrm{a}$ \\
\hline hAGT2 & 514 & Mito. & T09B4.8 & 444 & $53 \%$ & $1 \cdot 10^{-165}$ \\
\hline hLDH & 332 & Cyt. & $\mathrm{LDH}-1$ & 333 & $54 \%$ & $6 \cdot 10^{-119}$ \\
\hline
\end{tabular}

418 Table 5. Glyoxylate and oxalate levels lysates of wild-type and mutant strains grown 419 with glyoxylate.

\begin{tabular}{|l|l|l|}
\hline Strain & nmol glyoxylate/mg total protein & nmol oxalate/mg total protein \\
\hline N2 Bristol & 2.48 & 21.8 \\
\hline agxt-1 & 2.88 & 35.8 \\
\hline ICl-1 & 2.22 & 26.9 \\
\hline agxt-1; icl-1 & 3.35 & 30.2 \\
\hline
\end{tabular}

C. elegans is a remarkably useful model system to understand protein folding 421 diseases and their pharmacological correction [67-69]. Our studies advance that the 422 nematode C.elegans could be a model for $\mathrm{PH} 1$. Although simultaneous inactivation of 423 agxt-1 and icl-1 genes does not result in a clear oxalate accumulation (see Table 5), we 424 cannot rule out the possibility of a hyperoxaluric phenotype under the appropriate stress.. 425 Alternatively, models expressing disease-associated variants of hAGT1 in C. elegans may 426 also provide a convenient in vivo platform to explore and dissect the complex protein 427 homeostasis defects associated with $\mathrm{PH} 1$-causing mutations. 


\section{Acknowledgments.}

We thank Prof. Jose Manuel Sanchez-Ruiz for support. This work was supported by the Spanish Ministry of Science and Innovation (CSD2009-00088, BIO2012-34937 and SAF2011-23933), Junta de Andalucia (P11-CTS-7187), FEDER Funds and the Oxalosis and Hyperoxaluria Foundation (to B.C.). A. L. P. acknowledges a Ramon y Cajal research contract (RyC2009-04147) from the Spanish ministry of Science and Innovation and the University of Granada. N. M-T acknowledges a FPI predoctoral fellowship from the Spanish Ministry of Science and Innovation. A.C.C. and N.T. were supported by the grant IOS-1353845 from the National Science Foundation (NSF). N.T. acknowledges the Tetelman Fellowship for International Research on the Sciences awarded by Yale University.

References [1] Danpure CJ. Variable peroxisomal and mitochondrial targeting of alanine: glyoxylate aminotransferase in mammalian evolution and disease. Bioessays 1997;19:317-26. doi:10.1002/bies.950190409.

[2] Salido E, Pey AL, Rodriguez R, Lorenzo V. Primary hyperoxalurias: disorders of glyoxylate detoxification. Biochim Biophys Acta 2012;1822:1453-64. doi:10.1016/j.bbadis.2012.03.004.

[3] Baker PRS, Cramer SD, Kennedy M, Assimos DG, Holmes RP. Glycolate and glyoxylate metabolism in HepG2 cells. Am J Physiol Cell Physiol 2004;287:C1359_ 65. doi:10.1152/ajpcell.00238.2004.

[4] Caplin B, Wang Z, Slaviero A, Tomlinson J, Dowsett L, Delahaye M, et al. Alanineglyoxylate aminotransferase-2 metabolizes endogenous methylarginines, regulates NO, and controls blood pressure. Arter Thromb Vasc Biol 2012;32:2892-900. doi:10.1161/ATVBAHA.112.254078. 
[5] Rodionov RN, Jarzebska N, Weiss N, Lentz SR. AGXT2: a promiscuous aminotransferase. Trends Pharmacol Sci 2014;35:575-82. doi:10.1016/j.tips.2014.09.005.

[6] Cellini B, Bertoldi M, Montioli R, Paiardini A, Borri Voltattorni C. Human wild-type alanine:glyoxylate aminotransferase and its naturally occurring G82E variant: functional properties and physiological implications. Biochem J 2007;408:39-50. doi:10.1042/BJ20070637.

[7] Oppici E, Montioli R, Cellini B. Liver peroxisomal alanine:glyoxylate aminotransferase and the effects of mutations associated with Primary Hyperoxaluria Type I: An overview. Biochim Biophys Acta 2015;1854:1212-9. doi:10.1016/j.bbapap.2014.12.029.

[8] C. elegans Sequencing Consortium. Genome sequence of the nematode $C$. elegans: a platform for investigating biology. Science (80- ) 1998;282:2012-8.

[9] Kuwabara PE, O'Neil N. The use of functional genomics in C. elegans for studying human development and disease. J Inherit Metab Dis 2001;24:127-38.

[10] Colonna WJ, McFadden BA. Isocitrate lyase from parasitic and free-living nematodes. Arch Biochem Biophys 1975;170:608-19.

[11] Kornberg HL, Madsen NB. Synthesis of C4-dicarboxylic acids from acetate by a glyoxylate bypass of the tricarboxylic acid cycle. Biochim Biophys Acta 1957;24:651-3.

[12] Liu F, Thatcher JD, Barral JM, Epstein HF. Bifunctional glyoxylate cycle protein of Caenorhabditis elegans: a developmentally regulated protein of intestine and muscle. Dev Biol 1995;169:399-414. doi:10.1006/dbio.1995.1156.

[13] Khan FR, McFadden BA. Caenorhabditis elegans: decay of isocitrate lyase during 
larval development. Exp Parasitol 1982;54:47-54.

[14] Wadsworth WG, Riddle DL. Developmental regulation of energy metabolism in Caenorhabditis elegans. Dev Biol 1989;132:167-73.

[15] Pace CN, Vajdos F, Fee L, Grimsley G, Gray T. How to measure and predict the molar absorption coefficient of a protein. Protein Sci 1995;4:2411-23. doi:10.1002/pro.5560041120.

[16] Mesa-Torres N, Fabelo-Rosa I, Riverol D, Yunta C, Albert A, Salido E, et al. The Role of Protein Denaturation Energetics and Molecular Chaperones in the Aggregation and Mistargeting of Mutants Causing Primary Hyperoxaluria Type I. PLoS One 2013;8:e71963.

[17] Pey AL, Salido E, Sanchez-Ruiz JM. Role of low native state kinetic stability and interaction of partially unfolded states with molecular chaperones in the mitochondrial protein mistargeting associated with primary hyperoxaluria. Amino Acids 2011;41:1233-45. doi:10.1007/s00726-010-0801-2.

[18] Peterson EA, Sober HA. Preparation of Crystalline Phosphorylated Derivatives of Vitamin B6. J Am Chem Soc 1954;76:169-75. doi:10.1021/ja01630a045.

[19] Rumsby G, Weir T, Samuell CT. A semiautomated alanine:glyoxylate aminotransferase assay for the tissue diagnosis of primary hyperoxaluria type 1. Ann Clin Biochem 1997;34 ( Pt 4):400-4.

[20] Cellini B, Bertoldi M, Borri Voltattorni C. Treponema denticola cystalysin catalyzes beta-desulfination of L-cysteine sulfinic acid and beta-decarboxylation of L-aspartate and oxalacetate. FEBS Lett 2003;554:306-10.

[21] Sánchez-Ruiz JM, López-Lacomba JL, Cortijo M, Mateo PL. Differential scanning calorimetry of the irreversible thermal denaturation of thermolysin. Biochemistry 
1988;27:1648-52.

[22] Brenner S. The Genetics of Caenorhabditis Elegans. Genetics 1974;77:71-94.

[23] Mello C, Fire A. DNA transformation. Methods Cell Biol 1995;48:451-82.

[24] Zhang X, Roe SM, Hou Y, Bartlam M, Rao Z, Pearl LH, et al. Crystal structure of alanine:glyoxylate aminotransferase and the relationship between genotype and enzymatic phenotype in primary hyperoxaluria type 1. J Mol Biol 2003;331:643-52.

[25] Neupert W. Protein import into mitochondria. Annu Rev Biochem 1997;66:863-917. doi:10.1146/annurev.biochem.66.1.863.

[26] Claros MG, Vincens P. Computational method to predict mitochondrially imported proteins and their targeting sequences. Eur J Biochem 1996;241:779-86.

[27] Emanuelsson O, Brunak S, von Heijne G, Nielsen H. Locating proteins in the cell using TargetP, SignalP and related tools. Nat Protoc 2007;2:953-71. doi:10.1038/nprot.2007.131.

[28] Motley A, Lumb MJ, Oatey PB, Jennings PR, De Zoysa PA, Wanders RJ, et al. Mammalian alanine/glyoxylate aminotransferase 1 is imported into peroxisomes via the PTS1 translocation pathway. Increased degeneracy and context specificity of the mammalian PTS1 motif and implications for the peroxisome-to-mitochondrion mistargeting of . J Cell Biol 1995;131:95-109.

[29] Knott TG, Birdsey GM, Sinclair KE, Gallagher IM, Purdue PE, Danpure CJ. The peroxisomal targeting sequence type 1 receptor, Pex5p, and the peroxisomal import efficiency of alanine:glyoxylate aminotransferase. Biochem J 2000;352 Pt 2:409-18.

[30] Petriv OI, Pilgrim DB, Rachubinski $\mathrm{R}$ a, Titorenko VI. RNA interference of peroxisome-related genes in $C$. elegans: a new model for human peroxisomal 
disorders.

Physiol

Genomics

2002;10:79-91.

doi:10.1152/physiolgenomics.00044.2002.

[31] Motley AM, Hettema EH, Ketting R, Plasterk R, Tabak HF. Caenorhabditis elegans has a single pathway to target matrix proteins to peroxisomes. EMBO Rep 2000;1:40-6. doi:10.1038/sj.embor.embor626.

[32] Sievers F, Wilm A, Dineen D, Gibson TJ, Karplus K, Li W, et al. Fast, scalable generation of high-quality protein multiple sequence alignments using Clustal Omega. Mol Syst Biol 2011;7:539. doi:10.1038/msb.2011.75.

[33] McKay SJ, Johnsen R, Khattra J, Asano J, Baillie DL, Chan S, et al. Gene expression profiling of cells, tissues, and developmental stages of the nematode $C$. elegans. Cold Spring Harb Symp Quant Biol 2003;68:159-69.

[34] Dupuy D, Bertin N, Hidalgo CA, Venkatesan K, Tu D, Lee D, et al. Genome-scale analysis of in vivo spatiotemporal promoter activity in Caenorhabditis elegans. Nat Biotechnol 2007;25:663-8. doi:10.1038/nbt1305.

[35] Meissner B, Rogalski T, Viveiros R, Warner A, Plastino L, Lorch A, et al. Determining the sub-cellular localization of proteins within Caenorhabditis elegans body wall muscle. PLoS One 2011;6:e19937. doi:10.1371/journal.pone.0019937.

[36] Fares H, van der Bliek AM. Analysis of membrane-bound organelles. Methods Cell Biol 2012;107:239-63. doi:10.1016/B978-0-12-394620-1.00008-4.

[37] Curran SP, Leverich EP, Koehler CM, Larsen PL. Defective mitochondrial protein translocation precludes normal Caenorhabditis elegans development. J Biol Chem 2004;279:54655-62. doi:10.1074/jbc.M409618200.

[38] Billing O, Kao G, Naredi P. Mitochondrial function is required for secretion of DAF28/insulin in C. elegans. PLoS One 2011;6:e14507. 
doi:10.1371/journal.pone.0014507.

[39] Montioli R, Roncador A, Oppici E, Mandrile G, Giachino DF, Cellini B, et al. S81 L and G170R mutations causing Primary Hyperoxaluria Type I in homozygosis and heterozygosis: an example of positive interallelic complementation. Hum Mol Genet 2014. doi:10.1093/hmg/ddu329.

[40] Cellini B, Montioli R, Voltattorni CB. Human liver peroxisomal alanine:glyoxylate aminotransferase: characterization of the two allelic forms and their pathogenic variants. Biochim Biophys Acta 2011;1814:1577-84. doi:10.1016/j.bbapap.2010.12.005.

[41] Toney MD. Controlling reaction specificity in pyridoxal phosphate enzymes. Biochim Biophys Acta 2011;1814:1407-18. doi:10.1016/j.bbapap.2011.05.019.

[42] Chan P, Warwicker J. Evidence for the adaptation of protein $\mathrm{pH}$-dependence to subcellular pH. BMC Biol 2009;7:69. doi:10.1186/1741-7007-7-69.

[43] Robertson AD, Murphy KP. Protein Structure and the Energetics of Protein Stability. Chem Rev 1997;97:1251-68.

[44] Cellini B, Lorenzetto A, Montioli R, Oppici E, Voltattorni CB. Human liver peroxisomal alanine:glyoxylate aminotransferase: Different stability under chemical stress of the major allele, the minor allele, and its pathogenic G170R variant. Biochimie 2010;92:1801-11. doi:10.1016/j.biochi.2010.08.005.

[45] Birdsey GM, Lewin J, Cunningham AA, Bruford MW, Danpure CJ. Differential enzyme targeting as an evolutionary adaptation to herbivory in carnivora. Mol Biol Evol 2004;21:632-46. doi:10.1093/molbev/msh054.

[46] Danpure CJ, Fryer P, Jennings PR, Allsop J, Griffiths S, Cunningham A. Evolution of alanine:glyoxylate aminotransferase 1 peroxisomal and mitochondrial targeting. A 
survey of its subcellular distribution in the livers of various representatives of the classes Mammalia, Aves and Amphibia. Eur J Cell Biol 1994;64:295-313.

[47] Liu Y, Xu H, Yuan X, Rossiter SJ, Zhang S. Multiple adaptive losses of alanineglyoxylate aminotransferase mitochondrial targeting in fruit-eating bats. Mol Biol Evol 2012;29:1507-11. doi:10.1093/molbev/mss013.

[48] Purdue PE, Allsop J, Isaya G, Rosenberg LE, Danpure CJ. Mistargeting of peroxisomal L-alanine:glyoxylate aminotransferase to mitochondria in primary hyperoxaluria patients depends upon activation of a cryptic mitochondrial targeting sequence by a point mutation. Proc Natl Acad Sci U S A 1991;88:10900-4.

[49] Santana A, Salido E, Torres A, Shapiro LJ. Primary hyperoxaluria type 1 in the Canary Islands: a conformational disease due to $1244 \mathrm{~T}$ mutation in the P11Lcontaining alanine:glyoxylate aminotransferase. Proc Natl Acad Sci U S A 2003;100:7277-82. doi:10.1073/pnas.1131968100.

[50] Fargue S, Lewin J, Rumsby G, Danpure CJ. Four of the most common mutations in primary hyperoxaluria type 1 unmask the cryptic mitochondrial targeting sequence of alanine:glyoxylate aminotransferase encoded by the polymorphic minor allele. J Biol Chem 2013;288:2475-84. doi:10.1074/jbc.M112.432617.

[51] Somero GN. Adaptation of enzymes to temperature: searching for basic "strategies." Comp Biochem Physiol B Biochem Mol Biol 2004;139:321-33. doi:10.1016/j.cbpc.2004.05.003.

[52] Somero GN. Proteins and temperature. Annu Rev Physiol 1995;57:43-68. doi:10.1146/annurev.ph.57.030195.000355.

[53] Somero GN. Temperature adaptation of enzymes: biological optimization through structure-function comprimises. Annu Rev Ecol Syst 1978;9:1-29. 
[54] Oppici E, Montioli R, Lorenzetto A, Bianconi S, Borri Voltattorni C, Cellini B. Biochemical analyses are instrumental in identifying the impact of mutations on holo and/or apo-forms and on the region(s) of alanine:glyoxylate aminotransferase variants associated with primary hyperoxaluria type I. Mol Genet Metab 2012;105:132-40. doi:10.1016/j.ymgme.2011.09.033.

[55] O'Riordan VB, Burnell AM. Intermediary metabolism in the dauer larva of the nematode Caenorhabditis elegans - II. The glyoxylate cycle and fatty-acid oxidation. Comp Biochem Physiol Part B Comp Biochem 1990;95:125-30.

[56] Maeda I, Kohara Y, Yamamoto M, Sugimoto A. Large-scale analysis of gene function in Caenorhabditis elegans by high-throughput RNAi. Curr Biol 2001;11:1716.

[57] Hanazawa M, Mochii M, Ueno N, Kohara $\mathrm{Y}$, lino $\mathrm{Y}$. Use of cDNA subtraction and RNA interference screens in combination reveals genes required for germ-line development in Caenorhabditis elegans. Proc Natl Acad Sci U S A 2001;98:868691. doi:10.1073/pnas.141004698.

[58] Ashrafi K, Chang FY, Watts JL, Fraser AG, Kamath RS, Ahringer J, et al. Genomewide RNAi analysis of Caenorhabditis elegans fat regulatory genes. Nature 2003;421:268-72. doi:10.1038/nature01279.

[59] Braeckman BP, Houthoofd K, Vanfleteren JR. Intermediary metabolism. WormBook 2009:1-24. doi:10.1895/wormbook.1.146.1.

[60] Strittmatter L, Li Y, Nakatsuka NJ, Calvo SE, Grabarek Z, Mootha VK. CLYBL is a polymorphic human enzyme with malate synthase and beta-methylmalate synthase activity. Hum Mol Genet 2014. doi:10.1093/hmg/ddt624.

[61] Rubin H, Trelease RN. Subcellular localization of glyoxylate cycle enzymes in 
Ascaris suum larvae. J Cell Biol 1976;70:374-83.

[62] Patel TR, McFadden BA. Particulate isocitrate lyase and malate synthase in Caenorhabditis elegans. Arch Biochem Biophys 1977;183:24-30.

[63] Erkut C, Gade VR, Laxman S, Kurzchalia T V. The glyoxylate shunt is essential for desiccation tolerance in C. elegans and budding yeast. Elife 2016;5. doi:10.7554/eLife.13614.

[64] Kunze M, Pracharoenwattana I, Smith SM, Hartig A. A central role for the peroxisomal membrane in glyoxylate cycle function. Biochim Biophys Acta 2006;1763:1441-52. doi:10.1016/j.bbamcr.2006.09.009.

[65] Bolla R, Zuckerman BM, others. Nematode energy metabolism. Nematodes as Biol Model Vol 2 Aging Other Model Syst 1980:165-92.

[66] Adinolfi A, Moratti R, Olezza S, Ruffo A. Control of the citric acid cycle by glyoxylate. The mechanism of inhibition of oxoglutarate dehydrogenase, isocitrate dehydrogenase and aconitate hydratase. Biochem J 1969;114:513-8.

[67] Calamini B, Morimoto RI. Protein homeostasis as a therapeutic target for diseases of protein conformation. Curr Top Med Chem 2012;12:2623-40.

[68] Silva MC, Fox S, Beam M, Thakkar H, Amaral MD, Morimoto RI. A genetic screening strategy identifies novel regulators of the proteostasis network. PLoS Genet 2011;7:e1002438. doi:10.1371/journal.pgen.1002438.

[69] Casanueva MO, Burga A, Lehner B. Fitness trade-offs and environmentally induced mutation buffering in isogenic C. elegans. Science 2012;335:82-5. doi:10.1126/science.1213491. 